San Jose State University

SJSU ScholarWorks

Master's Theses

Master's Theses and Graduate Research

Fall 2016

\title{
Assessing Glacial Modification of Bedrock Valleys in the Sierra Nevada, California, Using a Novel Approach
}

Paul D. Zimmer

San Jose State University

Follow this and additional works at: https://scholarworks.sjsu.edu/etd_theses

\section{Recommended Citation}

Zimmer, Paul D., "Assessing Glacial Modification of Bedrock Valleys in the Sierra Nevada, California, Using a Novel Approach" (2016). Master's Theses. 4784.

DOI: https://doi.org/10.31979/etd.9epz-8s9p

https://scholarworks.sjsu.edu/etd_theses/4784

This Thesis is brought to you for free and open access by the Master's Theses and Graduate Research at SJSU ScholarWorks. It has been accepted for inclusion in Master's Theses by an authorized administrator of SJSU ScholarWorks. For more information, please contact scholarworks@sjsu.edu. 


\author{
A Thesis \\ Presented to \\ The Faculty of the Department of Geology \\ San José State University \\ In Partial Fulfillment \\ of the Requirements for the Degree \\ Master of Science
}

by

Paul D. Zimmer

December 2016 
(C)2016

Paul D. Zimmer

ALL RIGHTS RESERVED 
The Designated Thesis Committee Approves the Thesis Titled

\title{
ASSESSING GLACIAL MODIFICATION OF BEDROCK VALLEYS IN THE
}

SIERRA NEVADA, CALIFORNIA, USING A NOVEL APPROACH

\author{
by
}

Paul D. Zimmer

\section{APPROVED FOR THE DEPARTMENT OF GEOLOGY}

SAN JOSÉ STATE UNIVERSITY

December 2016
Dr. Emmanuel Gabet
Department of Geology
Dr. Paula Messina
Department of Geology
Dr. Jonathan Miller
Department of Geology 


\begin{abstract}
ASSESSING GLACIAL MODIFICATION OF BEDROCK VALLEYS IN THE SIERRA NEVADA, CALIFORNIA, USING A NOVEL APPROACH
\end{abstract}

\author{
by Paul D. Zimmer
}

This study employed a semi-automated approach to evaluate the degree of glacial modification of bedrock valleys in the Sierra Nevada, California, by quantifying morphological variability in cross-sectional form assessed from $\sim 27,000$ locations throughout the range. Measures of morphology including a shape ratio, a quadratic curve fit, and a power law curve fit were computed for each cross-section along with a novel metric, the V-index, and were compared to mapped glacial extent and bedrock lithology. Results indicate that Quaternary glaciations had a significant effect on bedrock valley morphology that is locally variable and largely independent of lithology at the range scale. Analysis of valley cross-sections and longitudinal profiles further suggest that glaciers in the Sierra Nevada modified pre-existing fluvial valleys primarily through widening. Moreover, the novel V-index is proposed as an alternative to traditional morphological measures due to its utility in describing irregular valley cross-sections and equivalent discriminatory power compared to established techniques for quantifying glacial geomorphology. 


\section{ACKNOWLEDGMENTS}

The author wishes to thank the members of his committee for generously providing their time and support to this research, as well the faculty of the Department of Geology at San José State University, Dr. Shannon Bros-Seemann, Ka’ai Jensen, Garrett Leidy, and my fellow undergraduate and graduate peers for their assistance along the way. 


\section{TABLE OF CONTENTS}

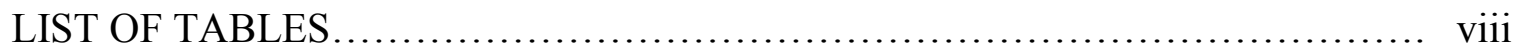

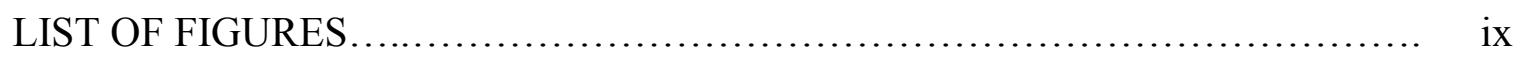

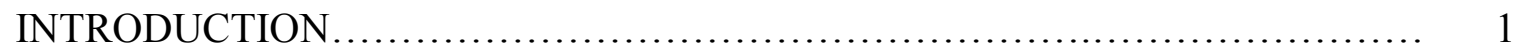

BEDROCK VALLEY FORMATION AND CONTROLS ......................... 3

Cross-sectional Form Development................................... 3

Longitudinal Profile Development....................................... 4

Controls on Valley Modification........................................ 5

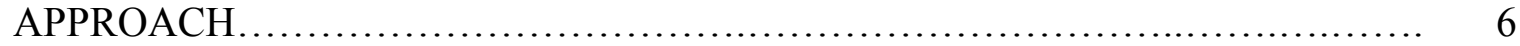

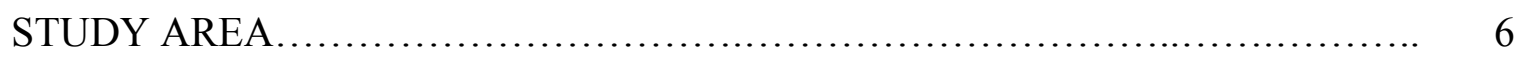

METHODS............................................................ 8

Valley Cross-Sections.............................................. 8

Longitudinal Profiles.................................................. 12

RESULTS................................................................. 12

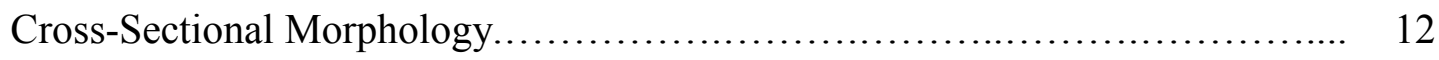

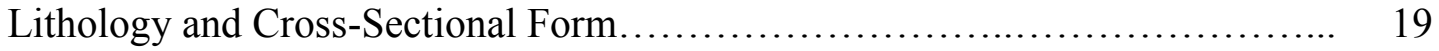

Longitudinal Profiles................................................. 21

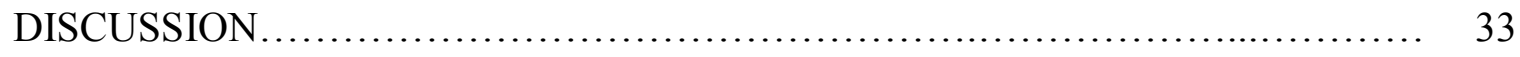

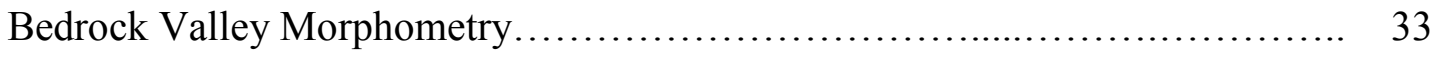

Longitudinal Profiles............................................... 37

Lithological Controls................................................... 37 
Semi-Automated Valley Analysis....................................... 38

Glacial Mapping Accuracy............................................ 40

Implications for Sierran Orogeny $\ldots \ldots \ldots \ldots \ldots \ldots \ldots \ldots \ldots \ldots \ldots \ldots \ldots \ldots \ldots \ldots . \quad 40$

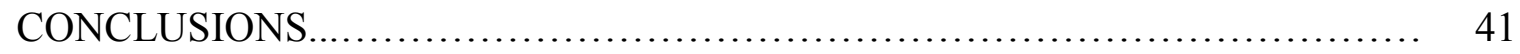

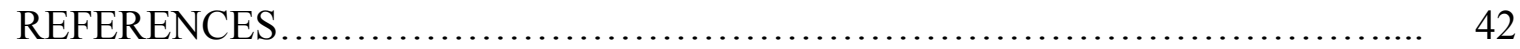

APPENDIX: MATLAB Script........................................ 49 


\section{LIST OF TABLES}

Table 1. Descriptive statistics for morphometry values................... 14

Table 2. Pearson correlation analysis - full valley versus truncated valley measures...................................................

Table 3. $\quad$ LRA results - full valley versus truncated valley measures........... 18

Table 4. LRA results $-\mathrm{V}$-index versus full valley power fitting $\ldots \ldots \ldots \ldots \ldots . . .18$

Table 5. Valley groups and corresponding rock type................................... 19

Table 6. Comparative statistics for northern and southern Sierra Nevada........ 35 


\section{LIST OF FIGURES}

Figure 1. Study area extent indicated by dashed line...................... 7

Figure 2. Example stream reaches showing 2-km wide cross-sections.......... 9

Figure 3. Illustration showing a range of $\mathrm{V}$-indices and corresponding valley forms........................................................... 10

Figure 4. Full valley cross-section compared to truncated valley crosssection.......................................................... 11

Figure 5. Distribution of cross-section locations and LGM extent............ 13

Figure 6. Box-and-whisker plots for select morphometry measures........... 15

Figure 7a. Longitudinal profile of North Yuba River....................... 23

Figure 7b. Longitudinal profile of Middle Yuba River....................... 23

Figure 7c. Longitudinal profile of South Yuba River........................ 24

Figure 7d. Longitudinal profile of North Fork American River................. 24

Figure 7e. Longitudinal profile of Middle Fork American River.............. 25

Figure 7f. Longitudinal profile of Rubicon River.......................... 25

Figure 7g. Longitudinal profile of Mokelumne River......................... 26

Figure 7h. Longitudinal profile of North Fork Stanislaus River............... 26

Figure 7i. Longitudinal profile of Middle Fork Stanislaus River............... 27

Figure 7j. Longitudinal profile of East Fork Carson River..................... 27

Figure 7k. Longitudinal profile of West Walker River...................... 28

Figure 71. Longitudinal profile of Cherry Creek............................. 28

Figure $7 \mathrm{~m} . \quad$ Longitudinal profile of Tuolumne River........................ 29 
Figure 7n. Longitudinal profile of Merced River....................... 29

Figure 7o. Longitudinal profile of South Fork Merced River................ 30

Figure $7 \mathrm{p} . \quad$ Longitudinal profile of San Joaquin River..................... 30

Figure 7q. Longitudinal profile of North Fork Kings River................ 31

Figure 7r. $\quad$ Longitudinal profile of Middle Fork Kings River................. 31

Figure 7s. Longitudinal profile of South Fork Kings River................ 32

Figure $7 \mathrm{t} . \quad$ Longitudinal profile of Kern River........................ 32

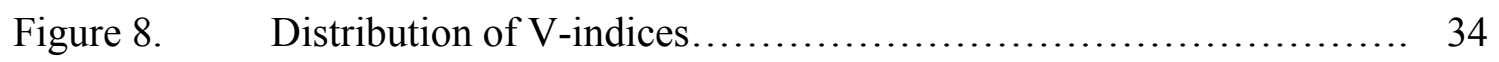

Figure 9. Relationship between V-index and elevation in study area.......... 36

Figure 10. Diagram illustrating major variables encoded by the script.............. 60 


\section{INTRODUCTION}

One of the fundamental assumptions in geomorphology is that the characteristics of a landscape contain information about the mechanisms that have produced the terrain-that form is derived from process. The ability to distinguish different landforms, both qualitatively and quantitatively, is therefore of primary importance in geomorphic research. The latter approach to land surface analysis is known as quantitative geomorphology or, when applied to digital terrain data, geomorphometry (Pike, 2008).

As a discipline, geomorphometry focuses on modeling continuous land surfaces derived from digital elevation datasets; extracting landforms, features, and attributes; and conducting geospatial analyses of surface characteristics (Pike, 2008). The field benefited greatly from, and has been arguably dependent upon, the introduction of digital elevation models (DEMs) in 1958 (Miller and Laflamme, 1958), which provided a framework for creating, storing, and manipulating digital elevation data.

Geomorphometric analysis has been applied to a variety of research problems, including landform discrimination (Liang and Xu, 2014), landslide hazard analysis (Dahal et al., 2008), and landscape evolution reconstruction (Montgomery, 2003), among others. Here, I employed a semi-automated morphometric approach to evaluate the degree of glacial modification of bedrock valleys in the Sierra Nevada, California, by quantifying morphological variability in cross-sectional form throughout the range.

The Sierra Nevada is the tallest and most continuous mountain chain in the contiguous United States (Martel et al., 2014). As such, considerable scientific research has focused on the origin and development of the range, with particular attention paid to its morphological 
characteristics. Supporters of the classic model of Sierran orogeny contend that the range rose in the Late Cenozoic as a single rotated block that was subsequently modified by topographic rejuvenation during uplift, an argument based on Eocene stream gradient reconstructions (Lindgren, 1911; Huber 1990), the tilt of basalt lava flows (Huber, 1981), and bedrock incision rates (Wakabayashi and Sawyer, 2001; Wakabayashi, 2013), among others. These studies relied on ambiguous interpretations, however, indicating the need to revisit some of their fundamental assumptions (Gabet, 2014). In contrast, studies utilizing stable isotope paleoaltimetry (Cassel et al., 2009a; Henry et al., 2012; Cassel et al., 2014), paleothermometry (Cecil, 2006; Mix et al., 2015), and topographic reconstructions based on Miocene and Pliocene ash-flows (Henry, 2008; Cassel et al., 2009b) support a model wherein the range has remained at high elevations since the late Cretaceous and may be the relict western edge of the Nevadaplano, a high-elevation orogenic plateau associated with the Sevier orogeny in the Basin and Range province (e.g., Cassel et al., 2012).

This latter view suggests that many of the morphological features typically associated with recent glacial incision and erosion, such as hanging tributaries and U-shaped troughs, may have formed under more ancient processes and climates than is currently understood. Given the importance ascribed to glacial erosion in shaping the topography of the Sierra Nevada (Matthes, 1930; Wahrhaftig and Birman, 1965), it is worth examining whether the classic "glacial" features of the range are exclusive to glacial environments and, conversely, whether the morphological characteristics of glaciated areas in the Sierra Nevada adhere to traditional models of glacial modification. 


\section{BEDROCK VALLEY FORMATION AND CONTROLS}

\section{Cross-sectional Form Development}

Differences in the erosional mechanics of fluvial and glacial processes can produce distinct bedrock valley cross-sectional forms, where stream valleys generally approach a Vshape while glaciers carve more rounded, U-shaped troughs (Bennett and Glasser, 2009). Consequently, the distribution of valley forms can provide a means of assessing the dominant processes that have acted upon the landscape, thereby offering valuable insight into the tectonic and climatic history of a region (Montgomery, 2003).

Fluvial modification of bedrock initially occurs as vertical incision in a channel; subsequent downcutting induces stresses on the channel walls, leading to slope failures that gradually widen the valley to a characteristic V-shape (Schumm and Ethridge, 1994). In certain cases, however, where downcutting is exceptionally fast or the stream erodes into very resistant rock, a slot or box canyon with vertical walls will form that does not approximate a V-shape, with Zion Canyon, Utah, being among the most notable examples (Rogers and Engelder, 2004).

While fluvial erosion is concentrated in the channel bottom, alpine glaciers typically flow down pre-existing stream valleys and produce stresses along the entire perimeter where the ice touches the valley sides (Ritter et al., 2011). A flowing glacier can modify these valleys by making them wider (Johnson, 1970; Hirano and Aniya, 1988), deeper (Harbor, 1990; 1992; Leith et al., 2014), or some combination of the two, resulting in a more U-shaped cross-section. While there is no consensus on the mechanics involved, glacial modification 
is a well-accepted process, having been observed on every continent (Aniya and Welch, 1981; Li et al., 2001) and other planets (Shean et al., 2007).

Valley cross-sectional profiles alone are not absolutely indicative of the formative processes that created them, as rivers can carve U-shaped canyons and glaciers can fail to modify pre-existing V-shaped forms (Augustinus, 1995). This ambiguity presents interpretive challenges that must be addressed carefully in studies of glacial geomorphology. While valley cross-sectional form has been shown to vary considerably in glaciated regions in the Sierra Nevada (Jensen, 2014), range scale investigations into valley morphology (e.g., Coles, 2014) are lacking in the Western Cordillera.

\section{Longitudinal Profile Development}

Fluvial and glacial processes can create not only characteristic cross-sectional forms but characteristic longitudinal profiles as well, which may provide additional insights into the tectonic and climatic history of a region. In a steady-state environment, an ideal stream longitudinal profile approaches a smooth, concave-up curve descending from the stream's headwaters to base level, representing an equilibrium between slope, downcutting, and deposition based on the competence of the stream, bedload, and lithology (Pazzaglia et al., 1998). Subsequent glacial modification of these graded streams can produce longitudinal profiles with steep headwalls and flattened gradients or overdeepenings near the terminal end of the glacier, and often produces a profile with a stepped or stair-tread appearance (Anderson et al., 2006). An ideal glacially-modified valley, then, would exhibit a distinct change in longitudinal profile form between glacial and fluvial erosional environments, distinguished by a nickpoint or abrupt change in channel slope. Although the Sierra Nevada 
contains flattened reaches and nickpoints that have been ascribed to glacial modification (e.g., Russell, 1889), other processes such as differential erosion (Wahrhaftig, 1965) and lithological controls (Matthes, 1930; Cassel and Graham, 2011; Johnson, 2015) have been suggested for their formation.

\section{Controls on Valley Modification}

Debate over the relative effectiveness of glacial and fluvial erosion has been ongoing for decades (see Hallet et al., 1996, for a general review), with researchers arguing for higher erosion rates in fluvial environments (e.g., Hicks et al., 1990; Hebdon et al., 1997) or in glacial settings (e.g., Harbor and Warburton, 1993; Montgomery, 2002; Naylor and Gabet, 2006). Studies specific to the Sierra Nevada have demonstrated that, while glaciers can produce greater relief in bedrock than fluvial processes (Brocklehurst and Whipple, 2002), glacial modification is strongly controlled by lithology and structure. Dühnforth et al. (2010) demonstrated that bedrock joint spacing presents a first-order constraint on glacial erosion rates and the predominant means of modification, with glacial erosion in areas of highly competent, unjointed bedrock being insignificant and limited to abrasion, while more fractured lithologies were subject to substantial modification due to quarrying. Becker et al. (2014) provided a corollary study arguing that variability in fracture density within a single bedrock lithology directly controlled glacial modification and subsequent landform development owing to differential erosion.

The hypothesis that lithology controls landscape evolution in the Sierra Nevada is not new, with François Matthes reaching that conclusion as early as the 1930s and writing later that "joints... are of supreme importance in understanding the sculpturing of Yosemite's 
walls" (Matthes and Fryxel, 1950, p. 109). The Sierra Nevada is composed of a variety of lithologies, including Paleozoic accreted terranes, Mesozoic plutonic rocks, and Cenozoic volcanic deposits (Irwin and Wooden, 2001), all of which have been subjected to Quaternary glaciations (Gillespie and Clarke, 2011). If rock strength and joint density present a firstorder control on glacial erosion mechanisms and rates in the Sierra Nevada, then variability in valley cross-sectional form may be constrained by lithology, with glacial modification restricted in massive unjointed rock while neighboring areas composed of more fractured or less competent material may exhibit greater alteration.

\section{APPROACH}

This study analyzed the spatial variability in bedrock valley cross-sectional morphology as a means of assessing the degree of glacial modification in the Sierra Nevada. Four different shape metrics were derived from $\sim 27,000$ cross-sections extracted from mosaicked 10-m DEMs of the Sierra Nevada, and the results were compared to mapped glacial extent and lithology. Additionally, $20 \mathrm{~km}$-long valley longitudinal profiles were derived from 20 glaciated stream reaches within the study area to evaluate the influence of glaciation and rock type on long profile morphology.

\section{STUDY AREA}

The valleys investigated in this study include all stream channels in the Sierra Nevada range that have incised into bedrock and produced at least $100 \mathrm{~m}$ of relief, including major rivers such as the Feather, Yuba, American, Mokelumne, Stanislaus, Tuolumne, Merced, San Joaquin, Kings, and Kern, as well as numerous other perennial, intermittent, and ephemeral streams (Figure 1). 


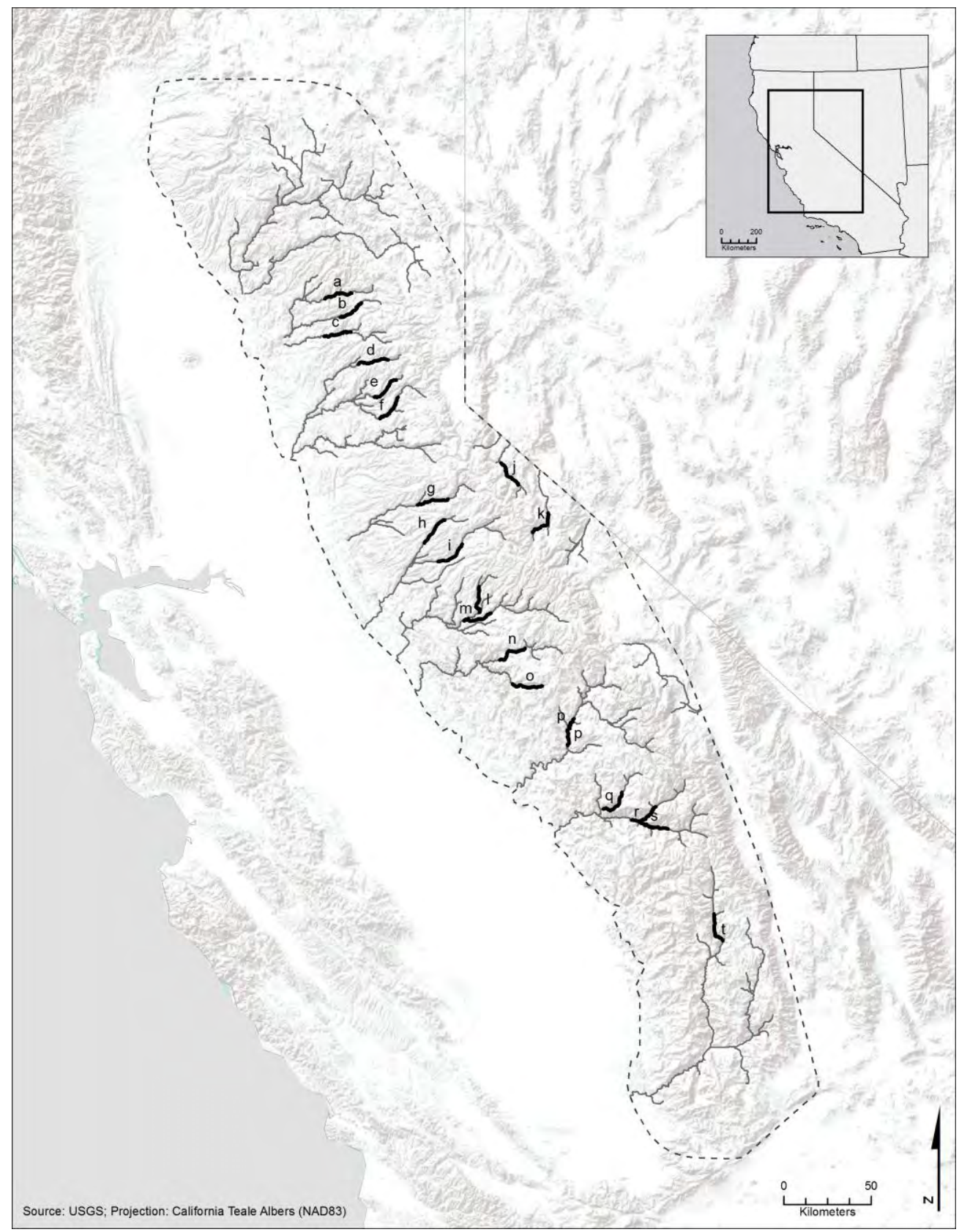

Figure 1. Study area extent indicated by dashed line. Major rivers indicated with light grey lines and bold lettered locations correspond to longitudinal profile reaches: a. North Yuba River, b. Middle Yuba River, c. South Yuba River, d. North Fork American River, e. Middle Fork American River, f. Rubicon River, g. Mokelumne River, h. North Fork Stanislaus River, i. Middle Fork Stanislaus, j. East Fork Carson River, k. West Walker River, 1. Cherry Creek, m. Tuolumne River, n. Merced River, o. South Fork Merced River, p. San Joaquin River, q. North Fork Kings River, r. Middle Fork Kings River, s. South Fork Kings River, and t. Kern River. 
Channels were defined by deriving a flow accumulation grid from 10-m DEMs and generating a vector dataset from cells with accumulation values greater than 10,000 . The resultant stream network was compared against the 1:100,000 scale National Hydrography Dataset (NHD) for California (U.S. Geological Society, 2012) for accuracy.

\section{METHODS}

The semi-automated approach used for data extraction and analysis of bedrock valley morphology in this study was accomplished using custom scripts written for MATLAB 2015 and ESRI ArcMap 10.3 software environments. Scripts were tested and calibrated using data with known morphometry values to ensure valid results.

\section{Valley Cross-Sections}

Cross-sections were automatically generated at regular intervals along every stream reach within the study area using the ET Geowizards Station Lines tool (Tchouchanski, 2016) in ArcMap 10.3. Cross-sections were set at $2000 \mathrm{~m}$ wide with $250 \mathrm{~m}$ spacing between locations to maximize the sample of valley types captured (small tributaries to trunk streams) and to provide comprehensive spatial coverage (Figure 2). To ensure that cross-sections were created perpendicular to valley trend, a smoothing function using a polynomial approximation with exponential kernel (PAEK) algorithm with 500-m tolerance was applied to the streamlines to remove orthogonal segments and provide more realistic stream geometry. Cross-sections located in reservoirs, lakes, or valleys with considerable alluvium covering bedrock (i.e., Yosemite Valley) were excluded from this study. Elevation profiles for each cross-section were derived from mosaicked 10-m DEMs and exported for processing 
in MATLAB, where a custom script isolated the target main valley in each cross-section and calculated form metrics for each location (the script is presented in the Appendix).

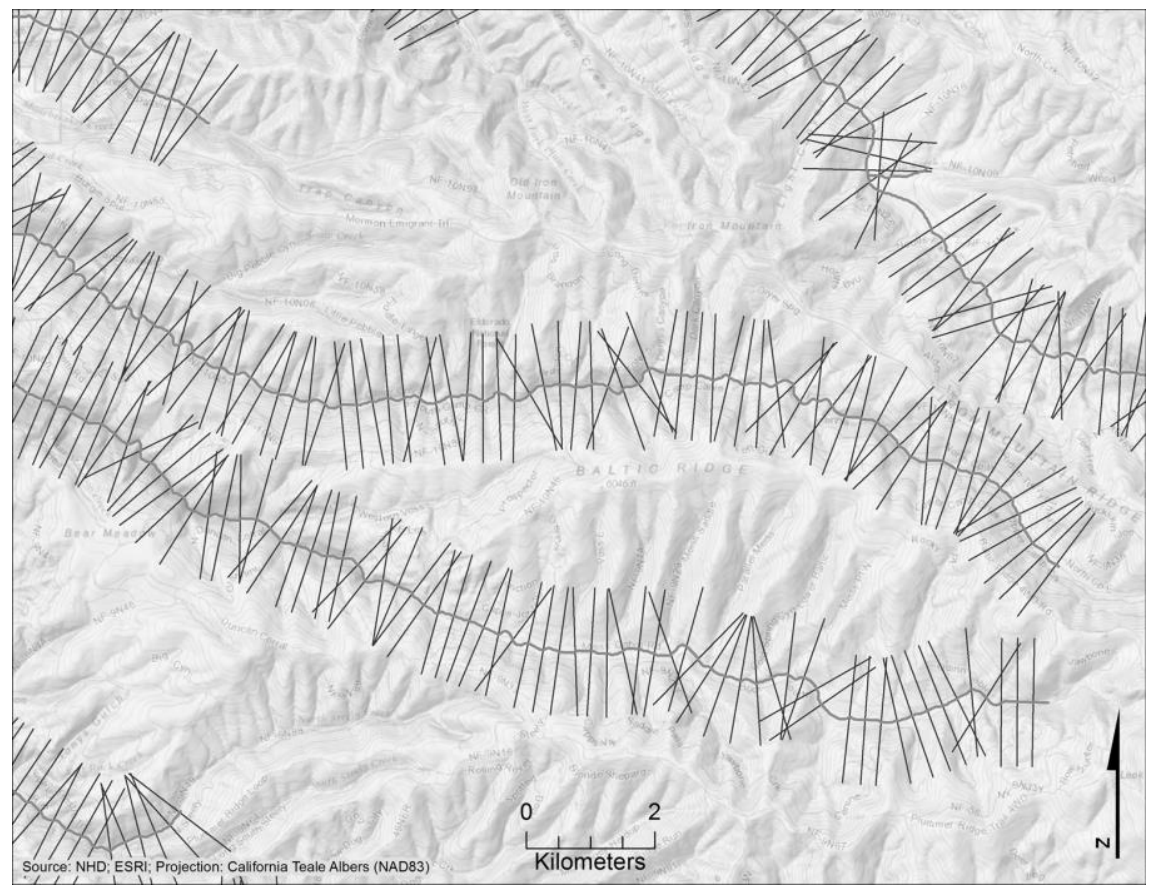

Figure 2. Example stream reaches showing 2-km wide cross-sections.

Morphometry values for this study included a shape ratio, quadratic curve fit, power curve fit, and a novel metric: the V-index. Shape ratios were derived following Bull and McFadden (1977), where valley width at 75 percent of valley height is divided by valley width at 25 percent of valley height. In this method, U-shaped valleys have lower values (approaching 1 for perfectly vertical walls) than $\mathrm{V}$-shaped valleys, which will have values greater than 1. For quadratic curve fitting, whole-valley cross-sections were fit to the quadratic equation $y=a+b x+c x^{2}$ (after Wheeler, 1984; James, 1996); in this approach, $x$ and $y$ are the horizontal and vertical coordinates along the valley while $a, b$, and $c$ are coefficients where $c$ directly controls valley shape, with larger values reflecting a narrower 
valley floor and therefore a more $\mathrm{V}$-shaped cross-section. Valley cross-sections were also fit to the general power law $y=a x^{b}$ using the Levenberg-Marquardt least squares method (after Augustinus, 1995; Brook et al., 2004). In this approach, $x$ and $y$ are the horizontal and vertical distances from the valley center, $a$ is a constant, and $b$ is a coefficient that describes valley curvature and generates values around 1 for $\mathrm{V}$-shaped valleys, while U-shaped valleys will feature $b$-values approaching 2 or greater. As power law fitting can only describe one half of a parabolic curve, each side of a cross-section was evaluated independently and the $b$ measures averaged for each location.

As an alternative approach, I used the V-index (Gabet, personal communication), which is calculated by comparing valley cross-sectional area $\left(A_{x}\right)$ below a standard benchmark height above the valley bottom to that of an ideal V-shaped cross-section with the same height and width as the subject cross-section $\left(A_{v}\right)$ with the form $V$-index $=\left(A_{x} / A_{v}\right)-1$.

This method measures the deviation from an ideal V-shaped valley, where a perfectly Vshaped cross-section will produce a $\mathrm{V}$-index value of 0 (no difference between computed and ideal); U-shaped valleys will have a V-index value greater than 0 ; and convex valley walls produce values less than 0 (Figure 3).

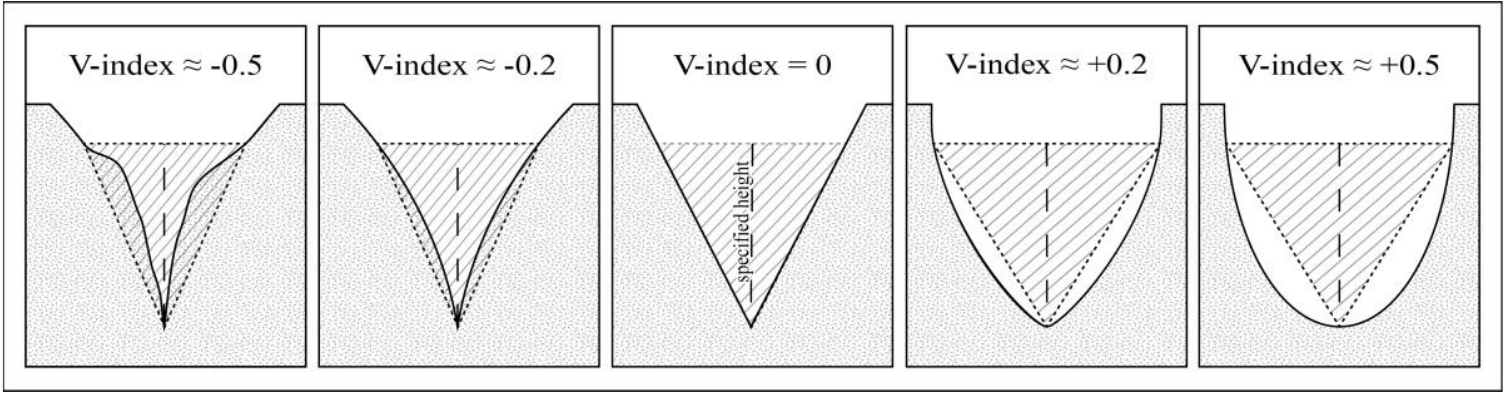

Figure 3. Illustration showing a range of $\mathrm{V}$-indices and corresponding valley forms 
Since the majority of glacial modification occurs in the lower portion of a valley (Bennett and Glasser, 2009), V-indices were calculated below a standard height of $100 \mathrm{~m}$ above the valley floor to allow for direct comparison of valleys of different depths across the range. This lower "truncated" valley is contrasted to the full valley, which is herein defined as the portion of a cross-section between the opposing peaks nearest to the valley bottom (Figure 4). Full valley cross-sections were clipped to the elevation of the lowest peak for processing. Curve-fitting and shape ratios were derived from the full valleys while all four metrics were evaluated for the truncated valleys to investigate the effects of cross-section truncation on morphometry measures.

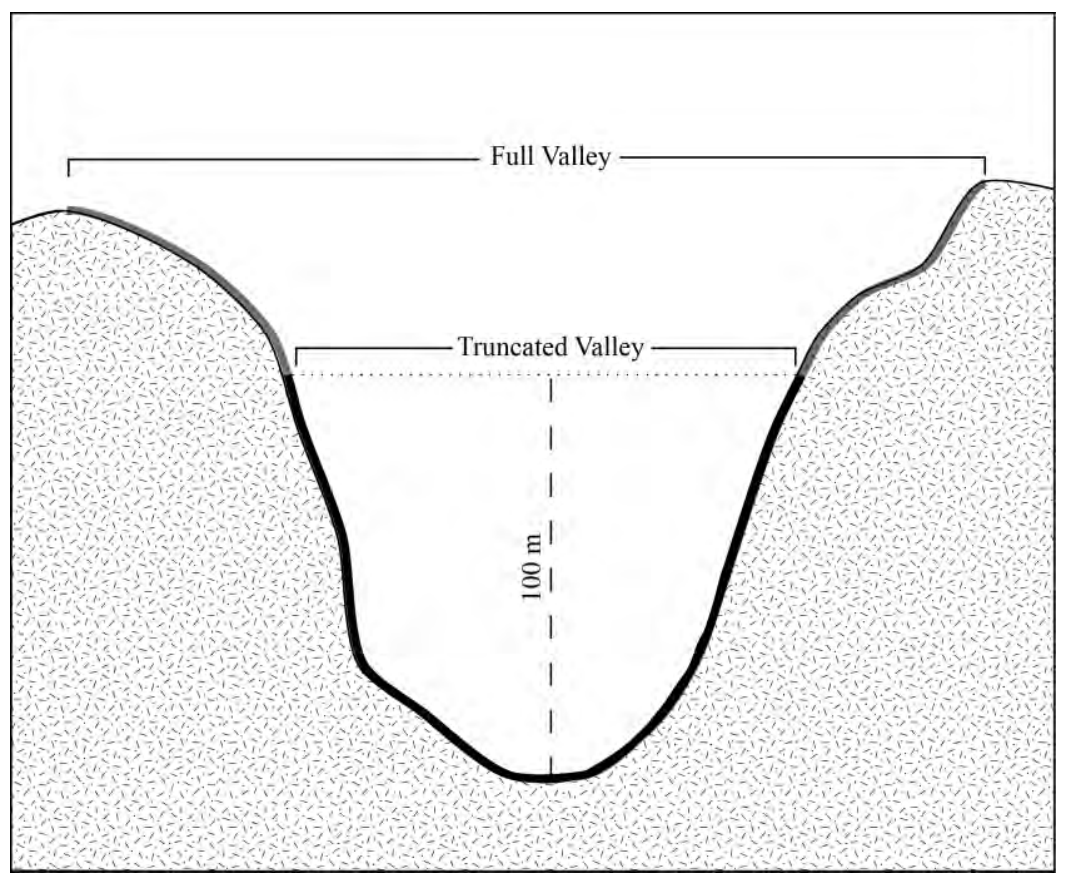

Figure 4. Full valley cross-section compared to truncated valley cross-section.

These data were then imported into ArcMap and compared to mapped limits of the Last Glacial Maximum (LGM) included in a digital dataset (Gillespie and Clark, 2011) and major 
lithological units provided in a 1:750,000 scale spatial dataset (U. S. Geological Survey, 2007).

\section{Longitudinal Profiles}

Longitudinal profiles of 20 streams featuring both glaciated and unglaciated reaches (identified in Figure 1) were extracted from 10-m resolution DEMs and clipped to $10 \mathrm{~km}$ upstream and downstream of the LGM limit to identify any correspondence between morphology, lithological units, and glacial extent.

\section{RESULTS}

\section{Cross-Sectional Morphology}

A total of 27,331 cross-sections were analyzed for this study (Figure 5), of which 6,858 were in glaciated terrain during the LGM and 20,473 were in unglaciated terrain (see Supplementary Materials for complete dataset). Table 1 lists descriptive statistics for the calculated morphometry values for all cross-sections within the study area. These results indicate that unglaciated valleys generally approximate a $\mathrm{V}$-shape while glaciated valleys are more U-shaped on average than unglaciated valleys, based on all metrics, although the range in values for both glaciated and unglaciated reaches indicates that $\mathrm{V}$-shaped and $\mathrm{U}$-shaped valleys are common in both (Figure 6). 


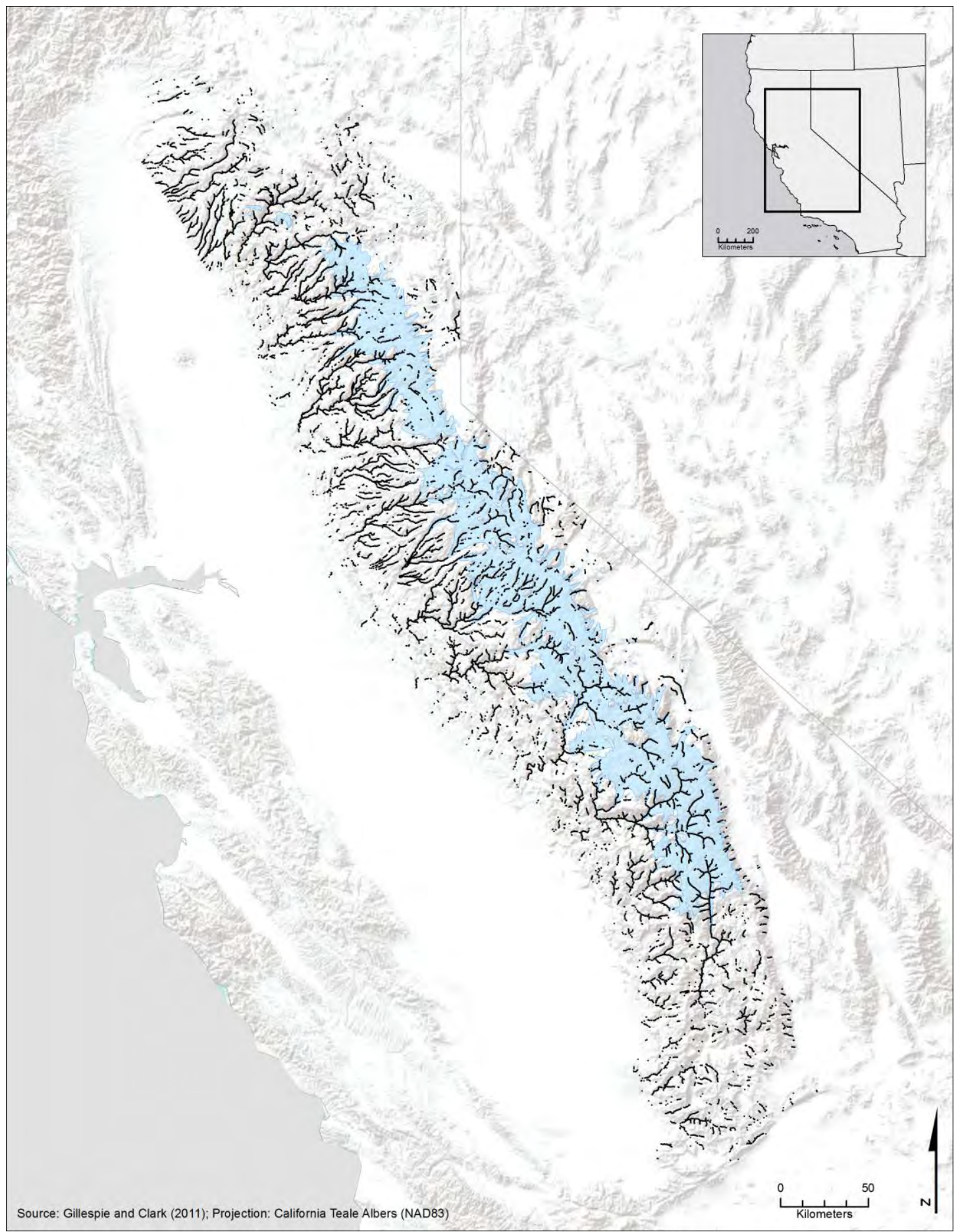

Figure 5. Distribution of cross-section locations and LGM extent. Cross-sections are indicated by black points and LGM extent shown in light blue. LGM data adapted from Gillespie and Clark (2011). 
Table 1. Descriptive statistics for morphometry values

\begin{tabular}{|c|c|c|c|c|c|c|}
\hline & & \multirow[b]{2}{*}{ Count } & \multirow[b]{2}{*}{ Mean } & \multirow[b]{2}{*}{$\begin{array}{r}\text { Std. } \\
\text { Deviation }\end{array}$} & \multicolumn{2}{|c|}{$\begin{array}{l}95 \% \text { Confidence } \\
\text { Interval for } \\
\text { Mean }\end{array}$} \\
\hline & & & & & $\begin{array}{l}\text { Lower } \\
\text { Bound }\end{array}$ & $\begin{array}{l}\text { Upper } \\
\text { Bound }\end{array}$ \\
\hline \multirow[t]{3}{*}{ V-index } & Glaciated & 6858 & 0.19 & 0.16 & 0.18 & 0.19 \\
\hline & Unglaciated & 20473 & 0.06 & 0.14 & 0.06 & 0.06 \\
\hline & Total & 27331 & 0.09 & 0.15 & 0.09 & 0.09 \\
\hline \multirow{3}{*}{$\begin{array}{l}\text { Power Law Fit }{ }^{1} \\
\text { (full valley) }\end{array}$} & Glaciated & 6858 & 1.34 & 0.43 & 1.33 & 1.35 \\
\hline & Unglaciated & 20473 & 1.04 & 0.31 & 1.04 & 1.02 \\
\hline & Total & 27331 & 1.12 & 0.37 & 1.11 & 1.12 \\
\hline \multirow{3}{*}{$\begin{array}{l}\text { Power Law Fit }{ }^{1} \\
\text { (truncated valley) }\end{array}$} & Glaciated & 6858 & 1.56 & 0.59 & 1.55 & 1.58 \\
\hline & Unglaciated & 20473 & 1.19 & 0.37 & 1.19 & 1.20 \\
\hline & Total & 27331 & 1.29 & 0.46 & 1.28 & 1.29 \\
\hline \multirow{3}{*}{$\begin{array}{l}\text { Quadratic Fit }{ }^{2} \\
\text { (full valley) }\end{array}$} & Glaciated & 6858 & 0.69 & 0.64 & 0.67 & 0.70 \\
\hline & Unglaciated & 20473 & 0.77 & 0.69 & 0.76 & 0.78 \\
\hline & Total & 27331 & 0.75 & 0.68 & 0.74 & 0.76 \\
\hline \multirow{3}{*}{$\begin{array}{l}\text { Quadratic Fit }^{2} \\
\text { (truncated valley) }\end{array}$} & Glaciated & 6858 & 1.45 & 1.59 & 1.41 & 1.49 \\
\hline & Unglaciated & 20473 & 1.92 & 1.75 & 1.90 & 1.95 \\
\hline & Total & 27331 & 1.81 & 1.72 & 1.78 & 1.83 \\
\hline \multirow{3}{*}{$\begin{array}{l}\text { Shape Ratio } \\
\text { (full valley) }\end{array}$} & Glaciated & 6858 & 2.41 & 0.76 & 2.39 & 2.42 \\
\hline & Unglaciated & 20473 & 3.00 & 0.90 & 2.99 & 3.02 \\
\hline & Total & 27331 & 2.85 & 0.90 & 2.84 & 2.86 \\
\hline \multirow{3}{*}{$\begin{array}{l}\text { Shape Ratio } \\
\text { (truncated valley) }\end{array}$} & Glaciated & 6858 & 2.25 & 0.74 & 2.24 & 2.27 \\
\hline & Unglaciate & 20473 & 2.69 & 0.82 & 2.68 & 2.70 \\
\hline & Total & 27331 & 2.58 & 0.82 & 2.57 & 2.59 \\
\hline
\end{tabular}

${ }^{1}$ Power fit values calculated by averaging left and right side $b$-exponents

${ }^{2}$ Quadratic fit values multiplied by $10^{3}$ 


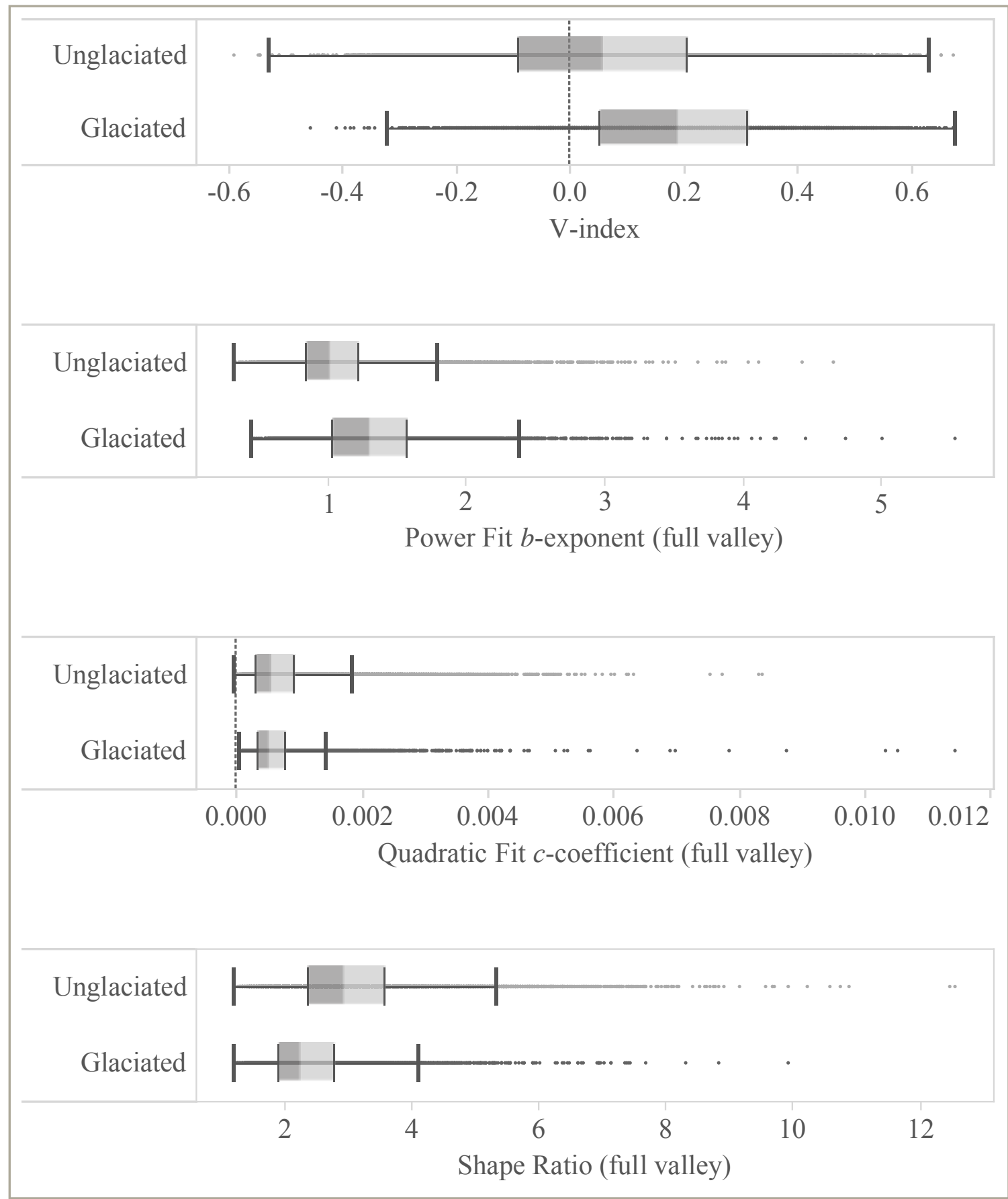

Figure 6. Box-and-whisker plots for select morphometry measures

Logistic regression analysis (LRA) was employed to assess the relative effectiveness of each metric in discriminating between glaciated and unglaciated valleys. LRA is a 
multivariate statistical technique used to describe the relationship between independent predictor variables (i.e., cross-section morphology values) and a dichotomous dependent variable (i.e., glaciated or unglaciated valley) by creating a model that measures the contribution of each independent variable in terms of probability in correctly predicting the state of the dependent variable (Pohar et al., 2004). More simply, LRA provides a relative measure of how well each variable is able to discriminate between a binary outcome, which, in this study, was whether a valley had been glaciated during the LGM.

Relevant output variables in LRA include a " $B$ " coefficient that represents the influence a given predictor variable has in determining the dependent variable, measured in log odds (logits); a p-value significance measure, where only those variables with $\mathrm{p}$ values $<0.05$ are considered significant for the purposes of this study; and $\exp (B)$, which transforms the log odds $(B)$ to an odds ratio. For example, a $B$ exponent of 2.0 would yield an $\exp (B)$ odds ratio of $\sim 7.4$, meaning that raising the predictor variable by 1 unit is 7.4 times more likely to change the state of the dependent variable. Thus, given a set of significant predictor variables (p-values $<0.05$ ), the variable with the highest $\exp (B)$ value has greater predictive power in determining the dependent variable, and therefore represents the more discriminating measure.

Analytical results reported here represent average values derived from five randomly sampled subsets containing equal numbers of glaciated $(\mathrm{n}=6858)$ and unglaciated $(\mathrm{n}=$ 6858) cross-sections. As highly correlated measures cannot be directly compared with regression analysis (Menard, 2002), a Pearson correlation procedure was conducted to determine the appropriate variables to include in the LRA for the full valley and truncated 
valley measures (Table 2). Covariates of full valley power fits with correlation indices larger than 0.70 were excluded from the LRA, and included truncated power fits and full valley shape ratios.

Table 2. Pearson correlation analysis - full valley versus truncated valley measures

\begin{tabular}{|c|c|c|c|c|c|c|}
\hline & & $\begin{array}{l}\text { Power Fit } \\
\text { (truncated) }\end{array}$ & $\begin{array}{r}\text { Quadratic } \\
\text { Fit (full) }\end{array}$ & $\begin{array}{r}\text { Quadratic Fit } \\
\text { (truncated) }\end{array}$ & $\begin{array}{r}\text { Shape Ratio } \\
\text { (full) }\end{array}$ & $\begin{array}{r}\text { Shape Ratio } \\
\text { (truncated) }\end{array}$ \\
\hline \multirow{3}{*}{$\begin{array}{l}\text { Power } \\
\text { Fit (full) }\end{array}$} & $\begin{array}{l}\text { Pearson } \\
\text { Correlation }\end{array}$ & 0.76 & -0.03 & -0.36 & -0.73 & -0.51 \\
\hline & $\begin{array}{l}\text { Sigma } \\
\text { (two-tailed) }\end{array}$ & 0.00 & 0.00 & 0.00 & 0.00 & 0.00 \\
\hline & Count & 13716 & 13716 & 13716 & 13716 & 13716 \\
\hline
\end{tabular}

Table 3 presents the regression analysis results, which indicate that full valley power fitting $(\exp (B)$ value of 11.18$)$ is the most effective predictor among the compared metrics in distinguishing glaciated valleys from unglaciated valleys. Although the truncated valley quadratic fits feature a very large $\exp (B)$ value, the measure does not exhibit the correct relationship with valley morphology, where a decrease in value indicates a more U-shaped cross-section. Rather, the truncated valley quadratic fits indicate the opposite relationship, where an increase in value is associated with a more U-shaped cross-section.

Given that full valley power fitting proved to be the most discriminatory of the traditional morphology measures, the predictive utility of the proposed V-index was compared to that of full valley power fits. Table 4 presents the LRA results comparing the $\mathrm{V}$-index to power curve fitting and indicates that both methods are equivalent in their ability to distinguish between glaciated and unglaciated valleys, with full valley power fits generating a predictive accuracy of $68.9 \%$ while the $\mathrm{V}$-index produces $68.1 \%$ accuracy. 
Table 3. LRA results - full valley versus truncated valley

\begin{tabular}{|c|c|c|c|c|c|c|c|c|}
\hline \multirow[b]{2}{*}{ Variable } & \multirow[b]{2}{*}{$B$} & \multirow[b]{2}{*}{ S.E. } & \multirow[b]{2}{*}{ Wald } & \multirow[b]{2}{*}{$d f$} & \multirow[b]{2}{*}{ Sig. } & \multirow[b]{2}{*}{$\operatorname{Exp}(B)$} & \multicolumn{2}{|c|}{$\begin{array}{l}95 \% \text { Confidence } \\
\text { Interval for } \operatorname{Exp}(\mathrm{B})\end{array}$} \\
\hline & & & & & & & Lower & Upper \\
\hline $\begin{array}{l}\text { Power Fit } \\
\text { (full) }\end{array}$ & 2.41 & 0.08 & 814.64 & 1.00 & 0.00 & 11.18 & 9.47 & 13.19 \\
\hline $\begin{array}{l}\text { Quadratic Fit } \\
\text { (full) }\end{array}$ & -330.44 & 38.13 & 75.11 & 1.00 & 0.00 & 0.00 & 0.00 & 0.00 \\
\hline $\begin{array}{l}\text { Quadratic Fit } \\
\text { (truncated) } \\
\text { Shape Ratio }\end{array}$ & 83.50 & 16.45 & 25.85 & 1.00 & 0.00 & $6.68 \mathrm{E}+38$ & $5.32 \mathrm{E}+24$ & $8.38 \mathrm{E}+52$ \\
\hline (full) & -0.24 & 0.03 & 60.17 & 1.00 & 0.00 & 0.79 & 0.74 & 0.84 \\
\hline Constant & -2.13 & 0.16 & 173.33 & 1.00 & 0.00 & 0.12 & - & - \\
\hline
\end{tabular}

Note: S.E. $=$ standard error; $\mathrm{df}=$ degrees of freedom; Sig. $=$ significance $(\mathrm{p}$-value $)$

Table 4. LRA results - V-index versus full valley power fitting

\begin{tabular}{lrr}
\hline \hline Pseudo-R $^{2}$ Values & & \\
& Cox \& Snell R & Nagelkerke ${ }^{2}$ \\
\hline Power Fit (full) & 0.14 & 0.20 \\
V-index & 0.15 & 0.20 \\
\hline
\end{tabular}

Classification Table

Observed

\begin{tabular}{|c|c|c|c|c|}
\hline & & Unglaciated & Glaciated & $\%$ Correct \\
\hline \multirow{3}{*}{ Power Fit (full) } & Unglaciated & 5189 & 1669 & 75.70 \\
\hline & Glaciated & 2593 & 4265 & 62.20 \\
\hline & & $111 \%$ & & 68.90 \\
\hline \multirow{3}{*}{ V-index } & Unglaciated & 4805 & 2053 & 70.10 \\
\hline & Glaciated & 2322 & 4536 & 66.10 \\
\hline & & $11 \%$ & & 68.10 \\
\hline
\end{tabular}

Goodness of fit values for both methods (pseudo- $\mathrm{R}^{2}$ values derived using Cox and Snell and Nagelkerke methods - approximately 0.14 and 0.20 , respectively) indicate a relatively weak relationship overall between prediction and grouping (Nagelkerke, 1991), likely 
reflecting the lack of a clear bimodal distribution of valley forms in the glaciated and unglaciated regions. Nevertheless, the $\sim 70 \%$ predictive success rate for power curve fitting and the V-index supports the overall utility of the methods for quantifying glaciated valleys.

\section{Lithology and Cross-Sectional Form}

While lithology has been shown to exert a first-order control on bedrock morphology in the Sierra Nevada (Becker et al., 2015; Johnson, 2015), this study indicates that glacial erosion is largely agnostic of rock type, having similarly impacted widely varying lithologies across the range. Table 5 shows the results of the morphometric analysis for major lithological groups in the study area using the $\mathrm{V}$-index.

Table 5. Valley groups and corresponding rock type

\begin{tabular}{cllrr}
\hline \hline Group & Rock Type & Glaciation & V-index & Count \\
\hline & argillite (metasedimentary) & Unglaciated & 0.059 & 4,253 \\
& \multirow{2}{*}{ peridotite } & Glaciated & 0.077 & 557 \\
& & Unglaciated & 0.060 & 368 \\
& \multirow{2}{*}{ sandstone } & Glaciated & 0.088 & 26 \\
& & Unglaciated & 0.069 & 277 \\
\cline { 2 - 5 } Group 1 & basalt & Glaciated & 0.055 & 6 \\
\cline { 3 - 5 } & \multirow{2}{*}{ slate } & Unglaciated & 0.104 & 48 \\
& & Glaciated & 0.174 & 2 \\
& \multirow{2}{*}{ hornfels } & Unglaciated & 0.111 & 598 \\
& & Glaciated & 0.181 & 176 \\
& \multirow{2}{*}{ dolostone (dolomite) } & Unglaciated & 0.308 & 7 \\
& & Glaciated & 0.211 & 66 \\
& andesite & Unglaciated & 0.218 & 8 \\
& & Glaciated & 0.299 & 25 \\
\hline \multirow{2}{*}{ felsic volcanics } & Unglaciated & 0.054 & 3,112 \\
& & Glaciated & 0.205 & 194 \\
& gabbro & Unglaciated & 0.039 & 7 \\
& & Glaciated & 0.199 & 315 \\
& & Unglaciated & 0.072 & 328 \\
& & Glaciated & 0.196 & 36 \\
\hline
\end{tabular}




\begin{tabular}{lllrr}
\hline \hline Group & Rock Type & Glaciation & V-index & Count \\
\hline & granodiorite & Unglaciated & 0.053 & 8,067 \\
& & Glaciated & 0.196 & 5,273 \\
& intermediate volcanics & Unglaciated & 0.057 & 1,055 \\
& & Glaciated & 0.122 & 90 \\
Group 2 & rhyolite & Unglaciated & 0.085 & 239 \\
& & Glaciated & 0.456 & 4 \\
& schist & Unglaciated & 0.072 & 1,141 \\
& & Glaciated & 0.201 & 84 \\
& tephrite (basanite) & Unglaciated & 0.005 & 15 \\
& & Glaciated & 0.032 & 4 \\
\hline & chert & Unglaciated & 0.092 & 3 \\
& greenstone & Unglaciated & 0.031 & 1 \\
& limestone & Unglaciated & 0.096 & 56 \\
& mafic volcanics & Unglaciated & 0.064 & 610 \\
Group 3 3 metasedimentary rock & Unglaciated & 0.000 & 25 \\
& metavolcanic rock & Unglaciated & 0.085 & 27 \\
& phyllite & Unglaciated & 0.052 & 20 \\
& plutonic rock (phaneritic) & Unglaciated & 0.054 & 187 \\
\cline { 2 - 5 } & conglomerate & Unglaciated & 0.168 & 20 \\
& mica schist & Unglaciated & 0.376 & 1 \\
\hline
\end{tabular}

Although sample sizes are not equal for each rock type, the data indicate three major groupings based on cross-sectional form. Group 1 is characterized by similar morphology in both glaciated and unglaciated valleys, where the ratio of glaciated V-indices $\left(V_{g}\right)$ to unglaciated $\mathrm{V}$-indices $\left(V_{u}\right)$ is less than $2\left(V_{g} / V_{u}<2\right)$. Within Group 1, argillite (metasedimentary), peridotite, and sandstone valleys tend toward V-shaped forms (average $V_{g}=0.073 ; V_{u}=0.063$ ), while basalt, slate, hornfels, and dolostone (dolomite) are more Ushaped (average $V_{g}=0.216 ; V_{u}=0.185$ ).

Group 2, which includes andesite, felsic volcanics, gabbro, granodiorite, intermediate volcanics, rhyolite, schist, and tephrite, shows a distinct difference in values between 
glaciated and unglaciated valleys where $V_{g} / V_{u}>2$, with an average $V_{g}=0.201$ and average $V_{u}=0.054$. Group 3 rocks, which include chert, conglomerate, greenstone, limestone, mafic volcanics, metasedimentary rock, metavolcanic rock, mica schist, phyllite, and phaneritic plutonic rocks, are only located in unglaciated areas and thus lacked corresponding glaciated samples for comparison. Within Group 3, the majority of rocks are predominantly V-shaped with $V_{u}$ values averaging 0.059 , while conglomerate and mica schist samples are more Ushaped, with $V_{u}$ values of 0.168 and 0.376 , respectively.

\section{Longitudinal Profiles}

Longitudinal profiles from the 20 glaciated stream reaches identified in Figure 1 are shown in Figures 7a-7t. The majority of streams $(n=14)$ show no distinct change between glaciated and unglaciated regions. Five streams, including the North Fork Mokelumne River (Figure 7g), Middle Fork Stanislaus River (Figure 7i), Cherry Creek (Figure 71), San Joaquin River (Figure 7p), and the North Fork Kings River (Figure 7q) feature reservoirs on or near the mapped divide between glaciated and unglaciated sections (indicated as a shaded area on each profile), while the small steps observable upstream of the LGM contact on the longitudinal profile for the Tuolumne River (Figure $7 \mathrm{~m}$ ) correspond to naturally occurring pools. Dashed lines on the respective figures indicate pre-dam long profiles derived from historic topographic maps, and most feature relatively smooth slopes with no evident overdeepening in the dammed locations, with the exceptions of Cherry Creek and the San Joaquin River. The bedrock surface below the Cherry Creek reservoir is relatively flat near the LGM contact and is bound by steeper slopes both upstream and downstream. The San Joaquin River reservoir (Mammoth Pools) is located $2 \mathrm{~km}$ upstream of the LGM contact and 
extends for more than $10 \mathrm{~km}$ over an historic bedrock channel that featured a $\sim 0.5 \%$ slope. The abrupt changes in channel slope noted for these two streams are potentially consistent with glacial modification of longitudinal profiles (e.g., Anderson et al., 2006).

Four additional reaches are suggestive of glacial modification of a graded profile: North Fork Stanislaus River (Figure 7h), the East Fork Carson River (Figure 7j), West Walker River (Figure 7k), and the Kern River (Figure 7t). The North Fork Stanislaus contains a distinct nickpoint and subdued step $4 \mathrm{~km}$ upstream of the mapped LGM limit in the valley. The East Fork Carson River is unique within this study in that it flows from south to north parallel to the range and features a distinctive stepped appearance with regular 1-2 km wide treads. Lithological mapping indicates that the river flows entirely within a landscape comprised of andesite and rhyolite, so the stair-tread appearance could potentially be ascribed to structural controls (lithology or faulting), glacial modification, or a combination thereof. 


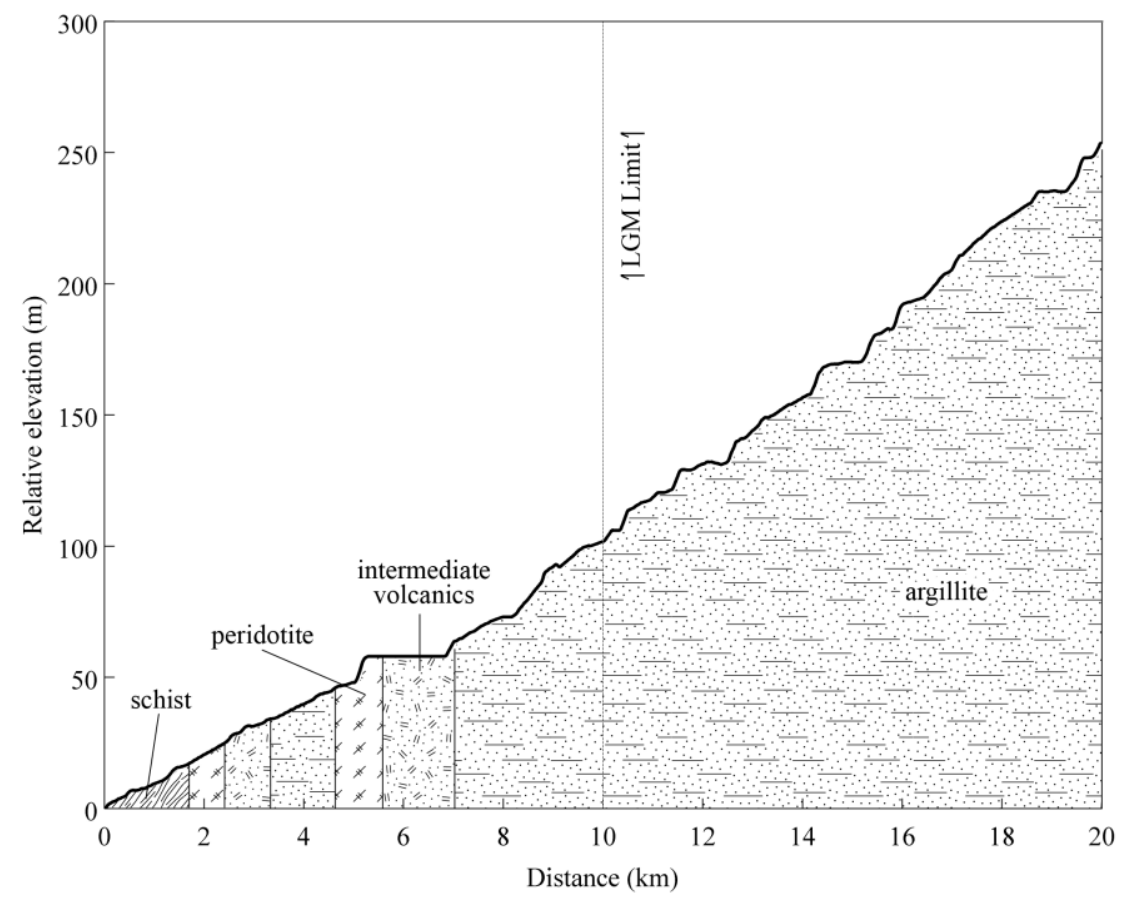

Figure 7a. Longitudinal profile of North Yuba River.

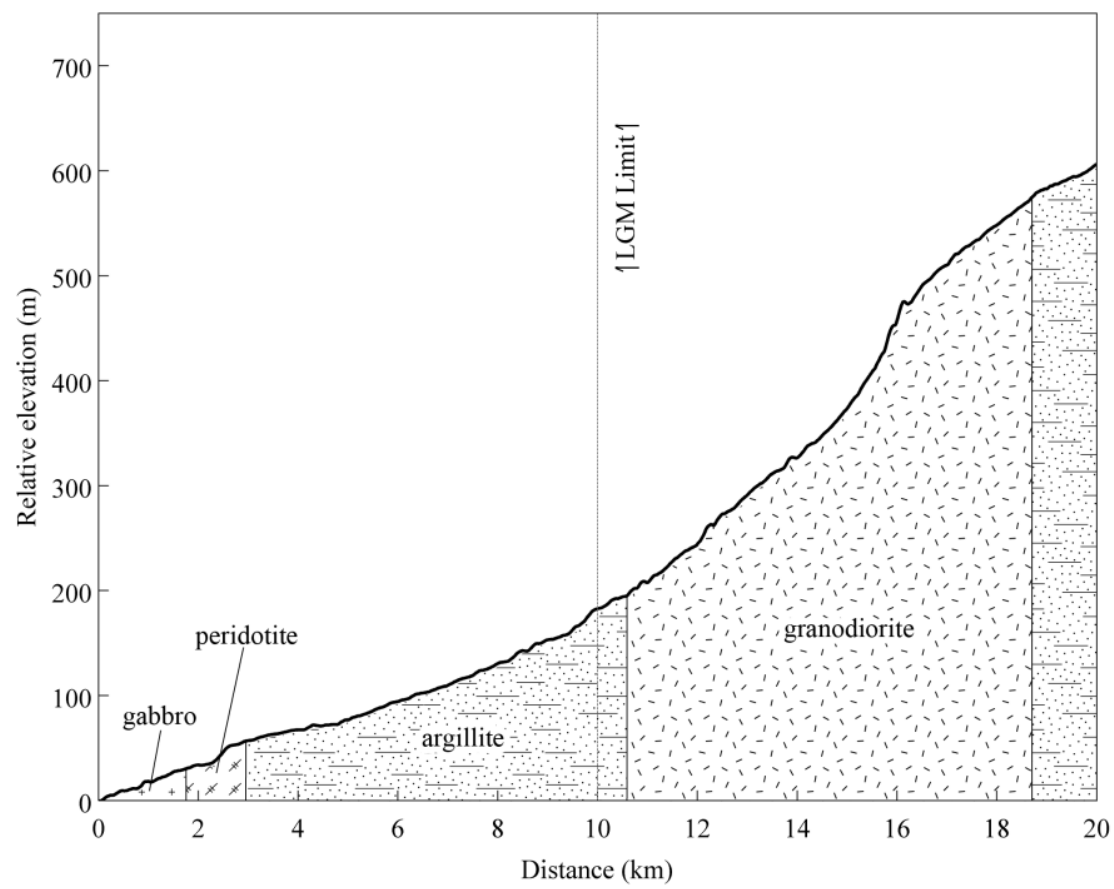

Figure 7b. Longitudinal profile of Middle Yuba River. 


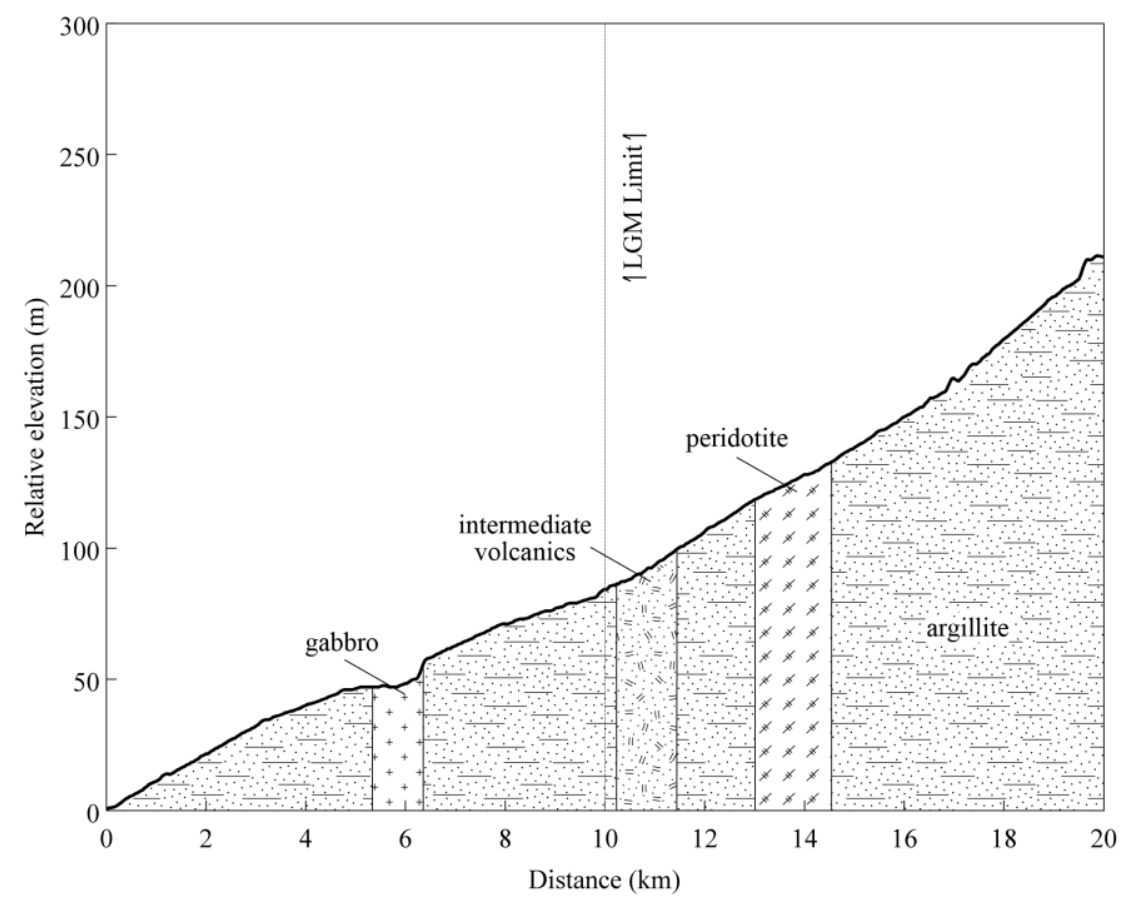

Figure 7c. Longitudinal profile of South Yuba River.

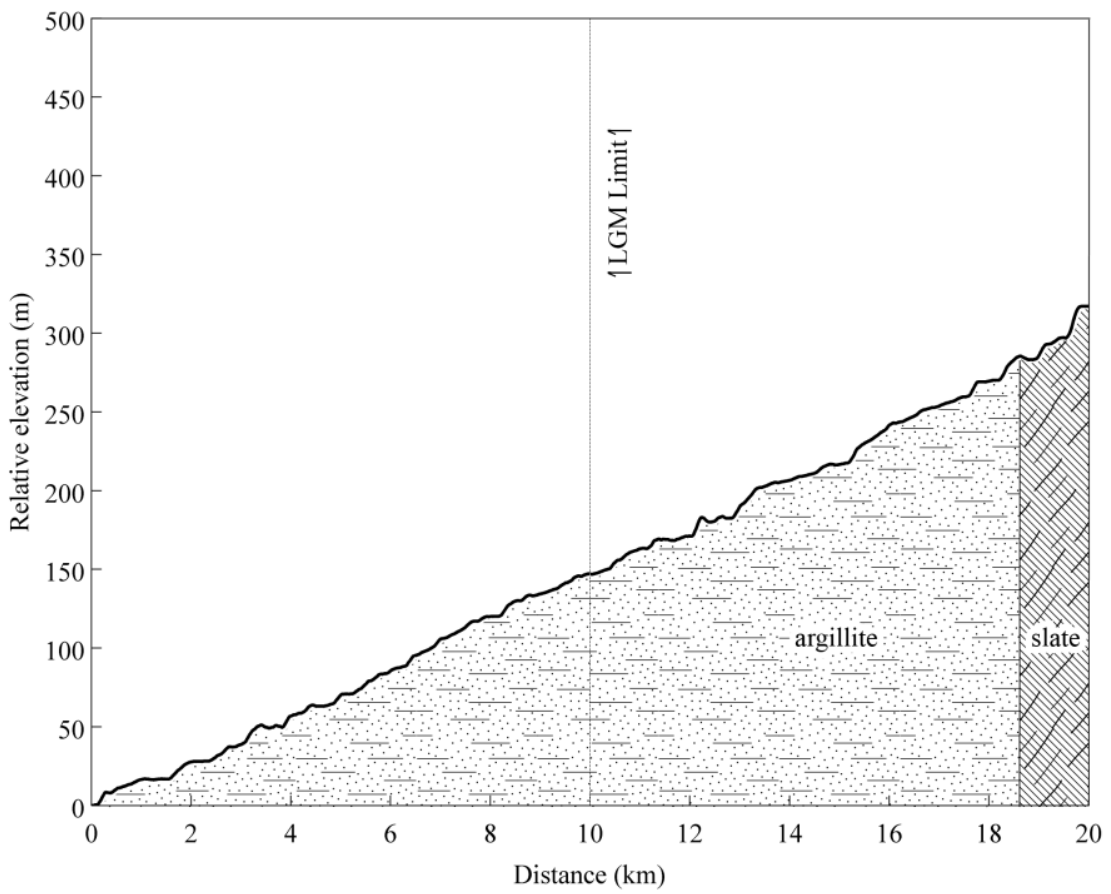

Figure 7d. Longitudinal profile of North Fork American River. 


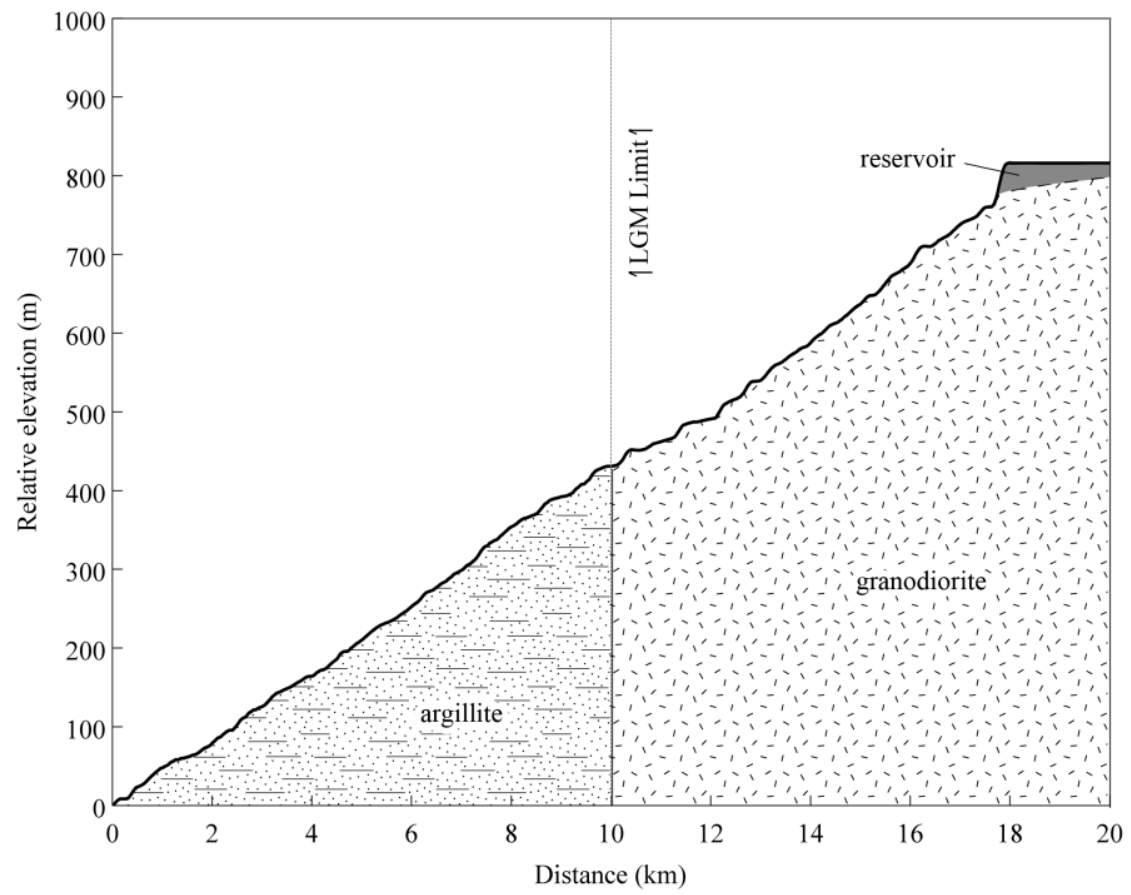

Figure 7e. Longitudinal profile of Middle Fork American River.

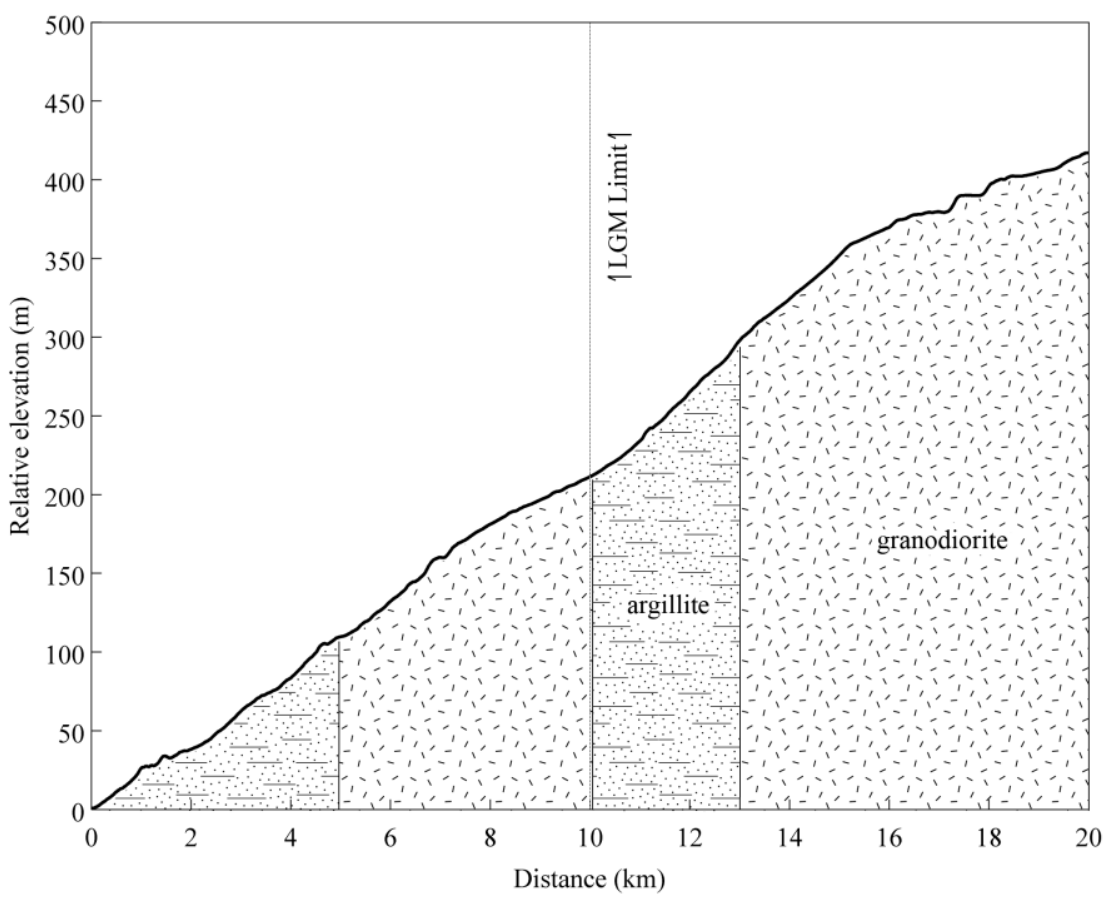

Figure 7f. Longitudinal profile of Rubicon River. 


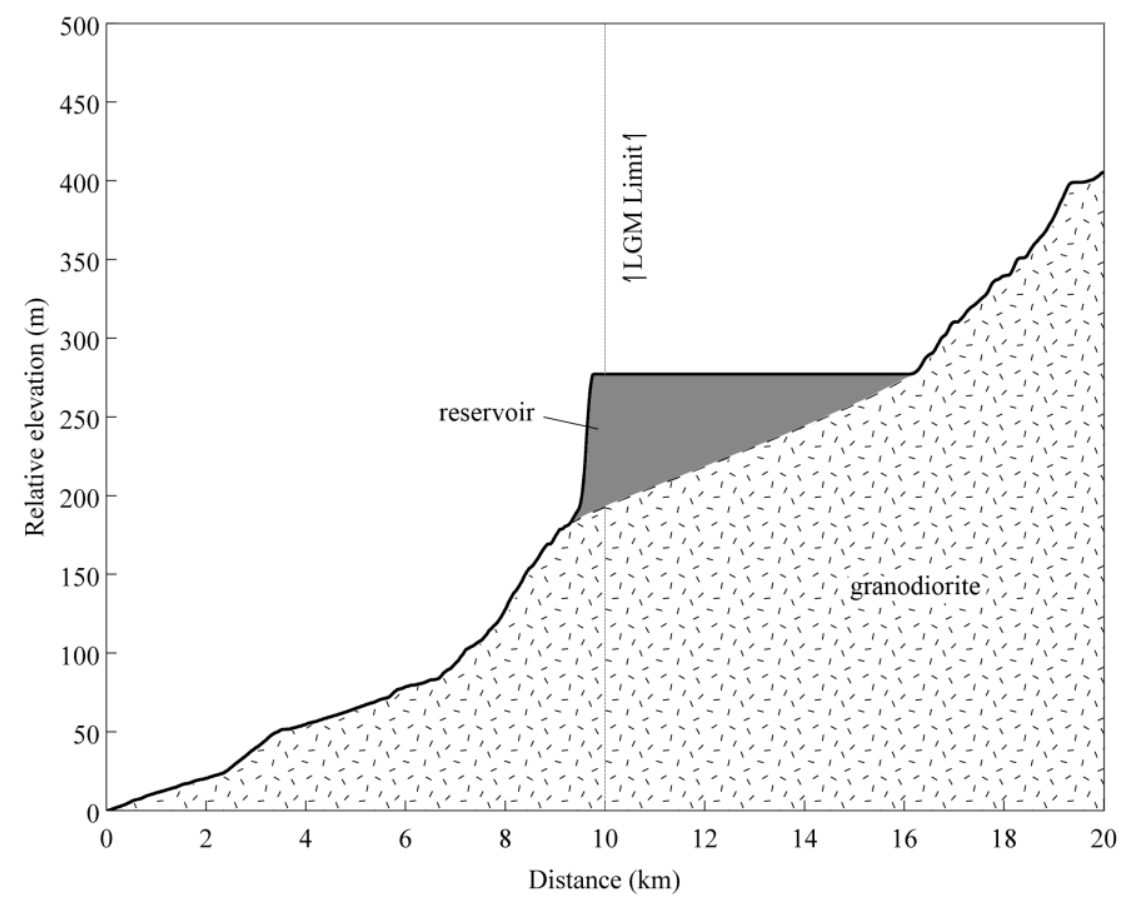

Figure 7g. Longitudinal profile of Mokelumne River.

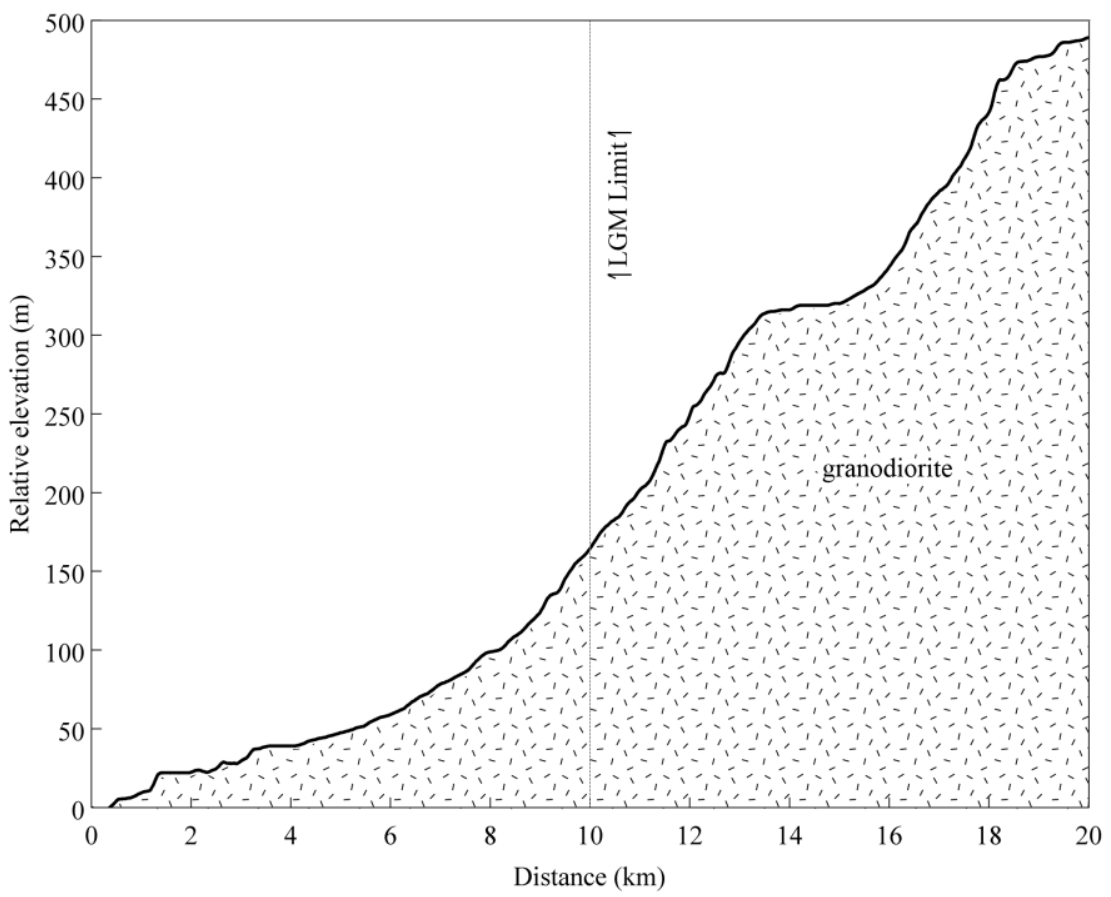

Figure 7h. Longitudinal profile of North Fork Stanislaus River. 


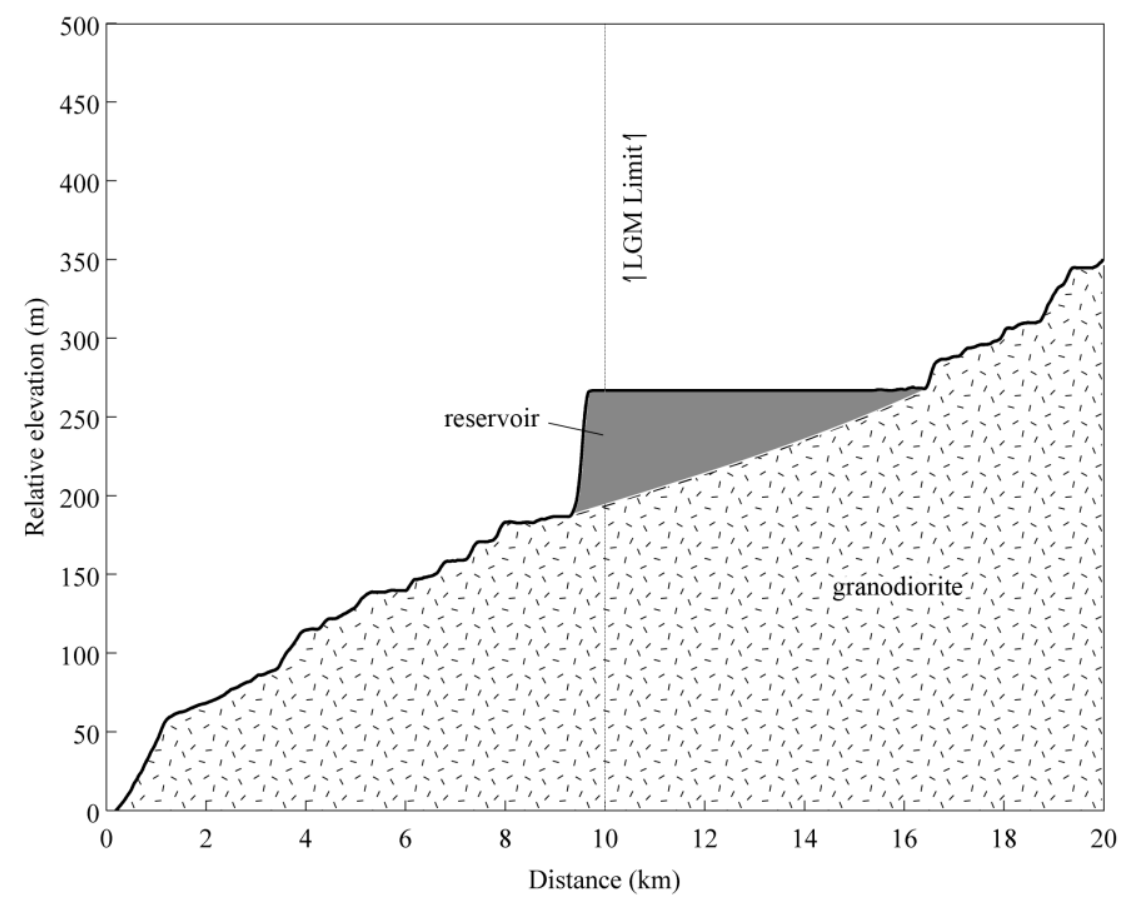

Figure 7i. Longitudinal profile of Middle Fork Stanislaus River.

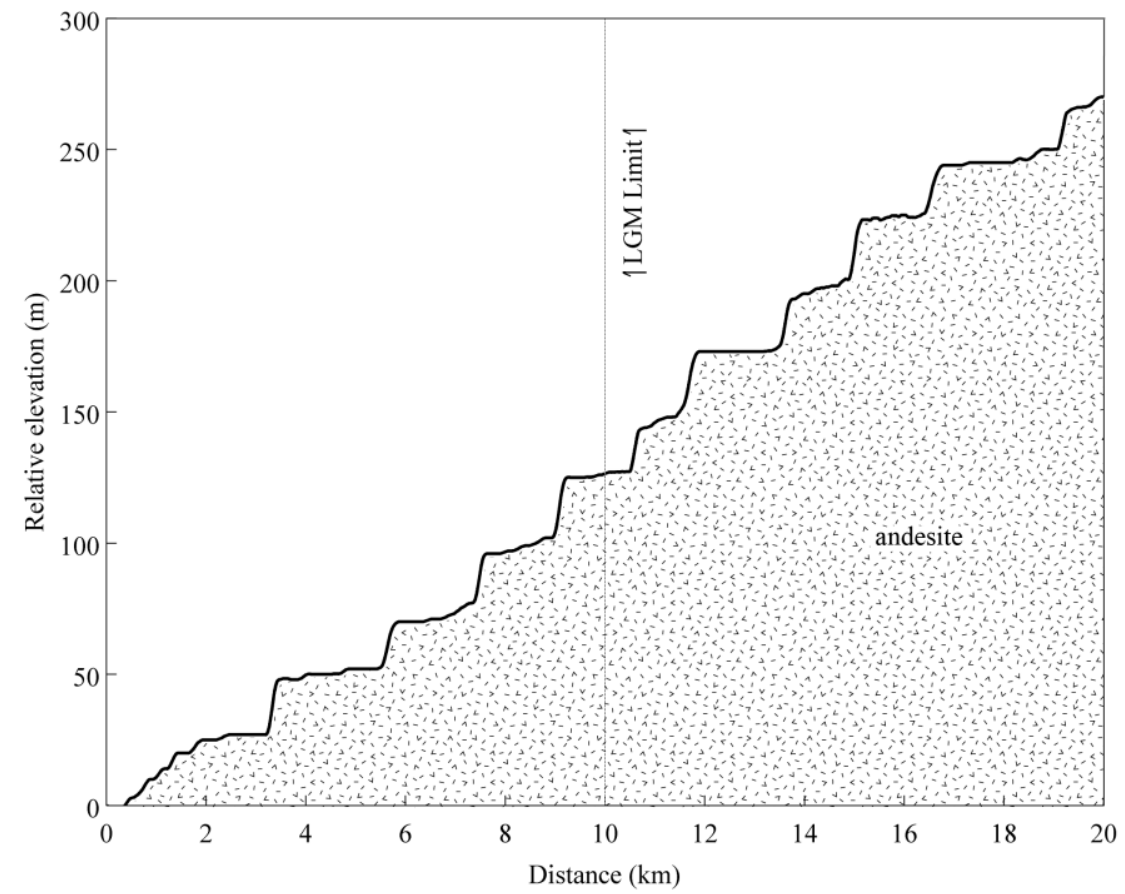

Figure 7j. Longitudinal profile of East Fork Carson River. 


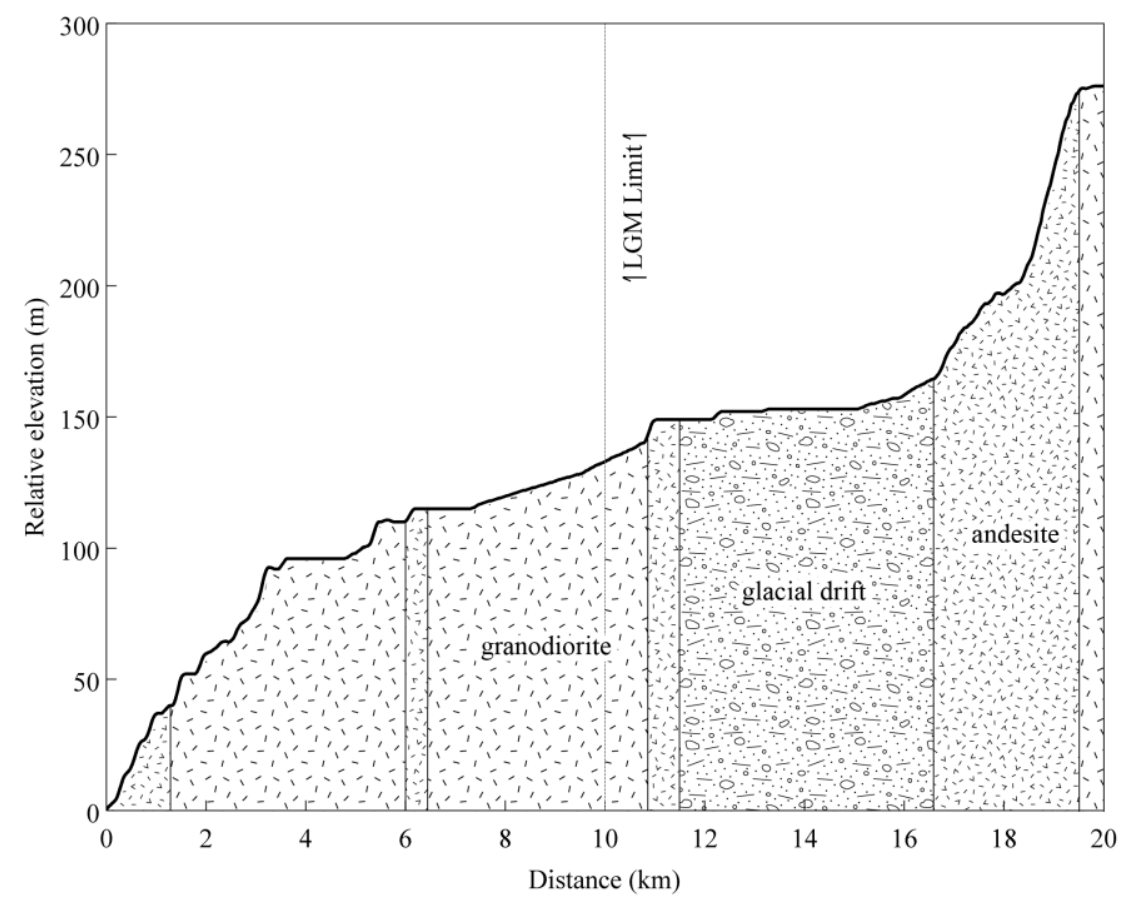

Figure 7k. Longitudinal profile of West Walker River.

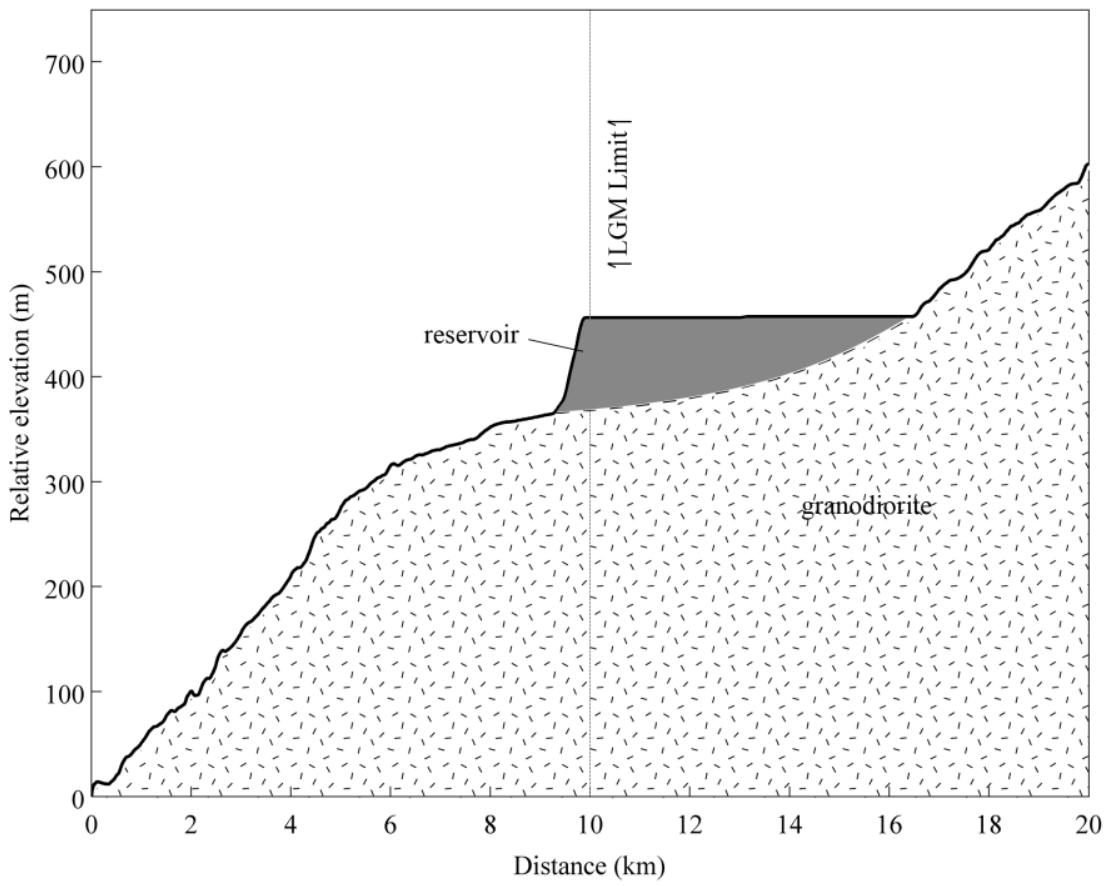

Figure 71. Longitudinal profile of Cherry Creek. 


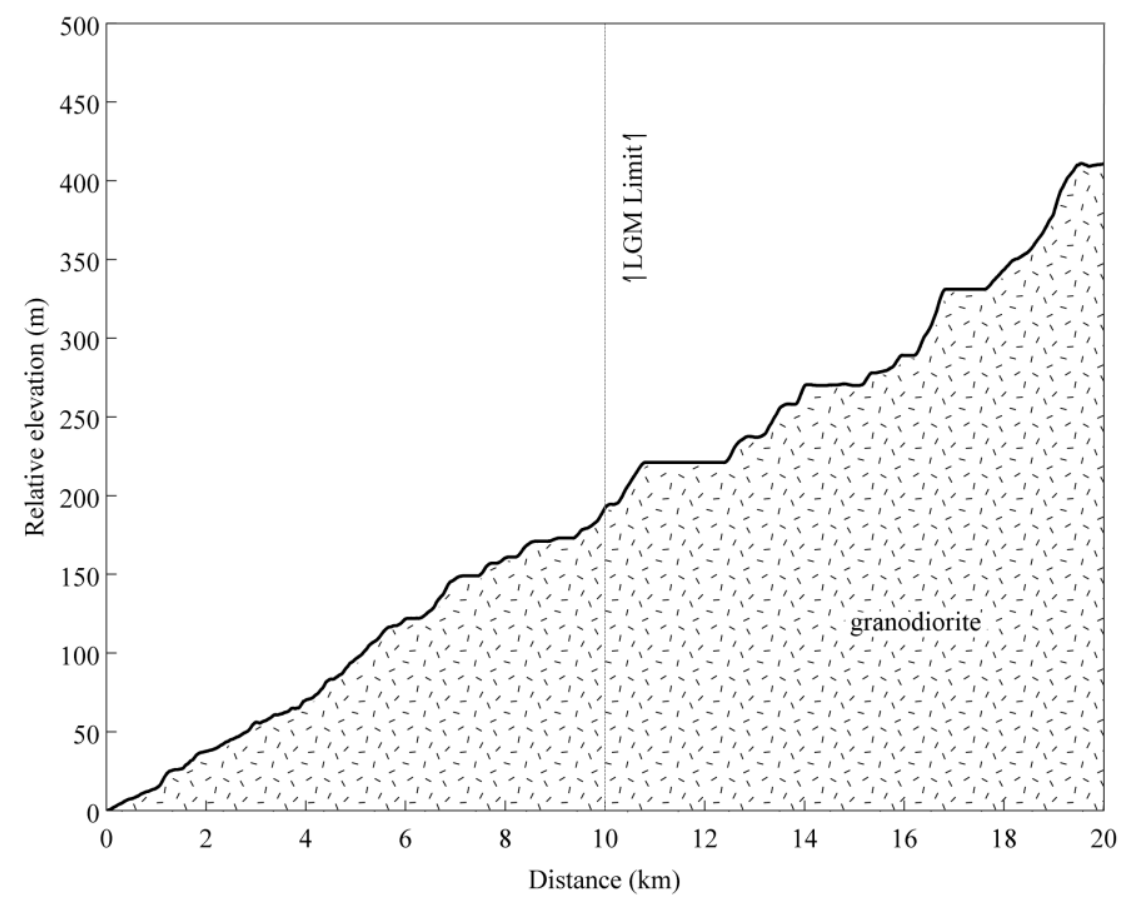

Figure $7 \mathrm{~m}$. Longitudinal profile of Tuolumne River.

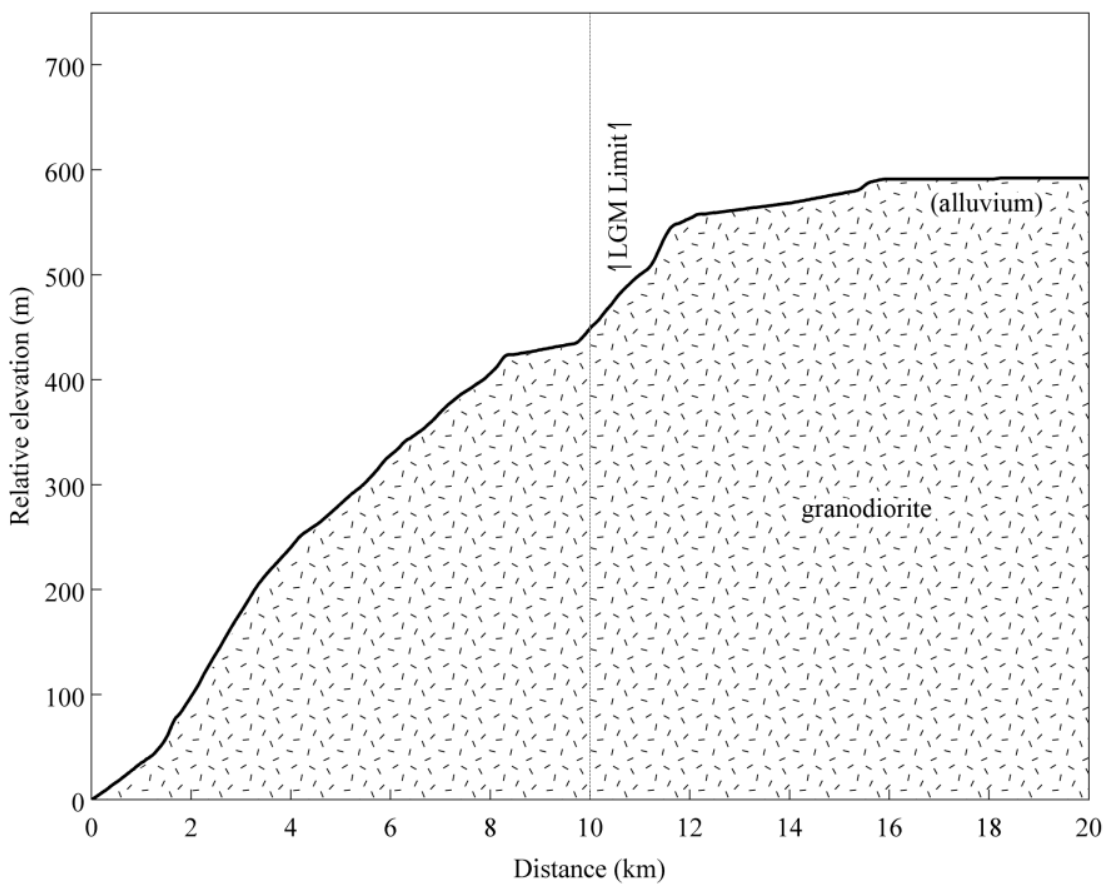

Figure 7n. Longitudinal profile of Merced River. 


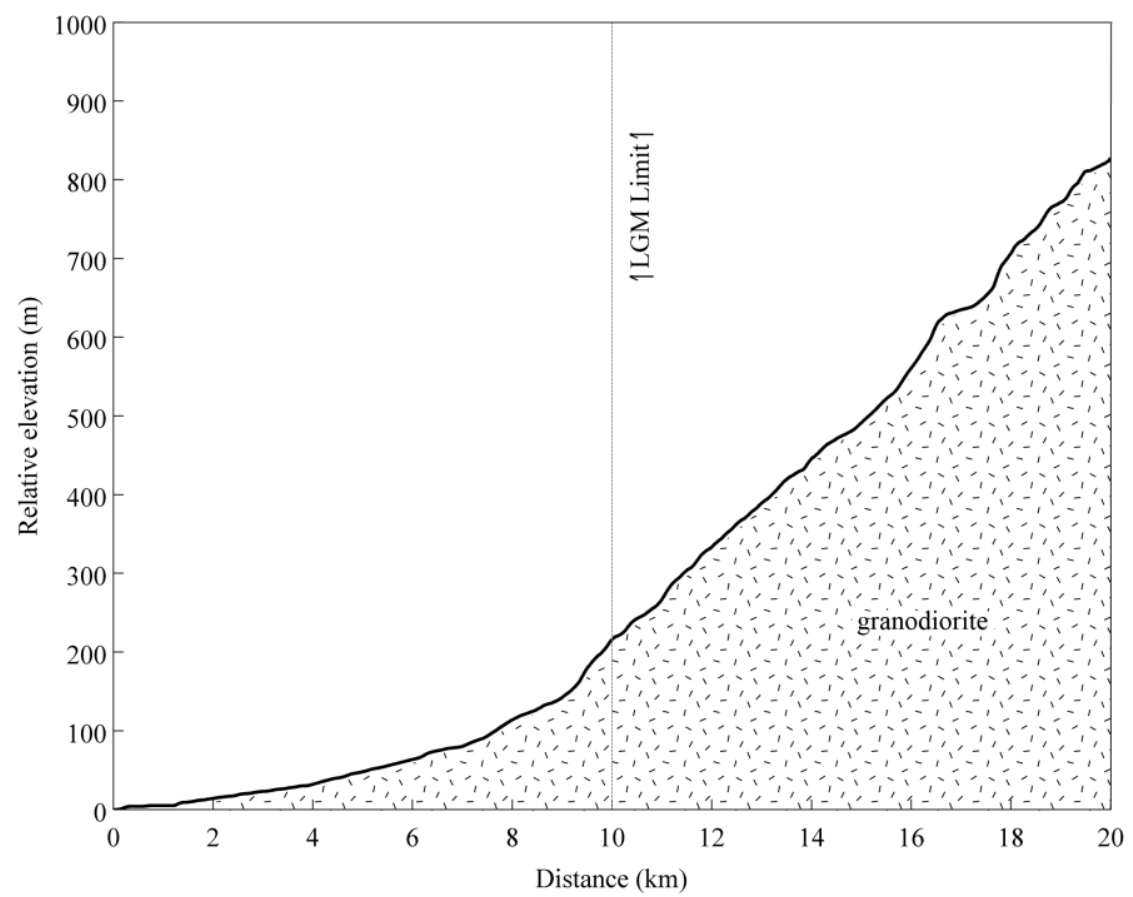

Figure 7o. Longitudinal profile of South Fork Merced River.

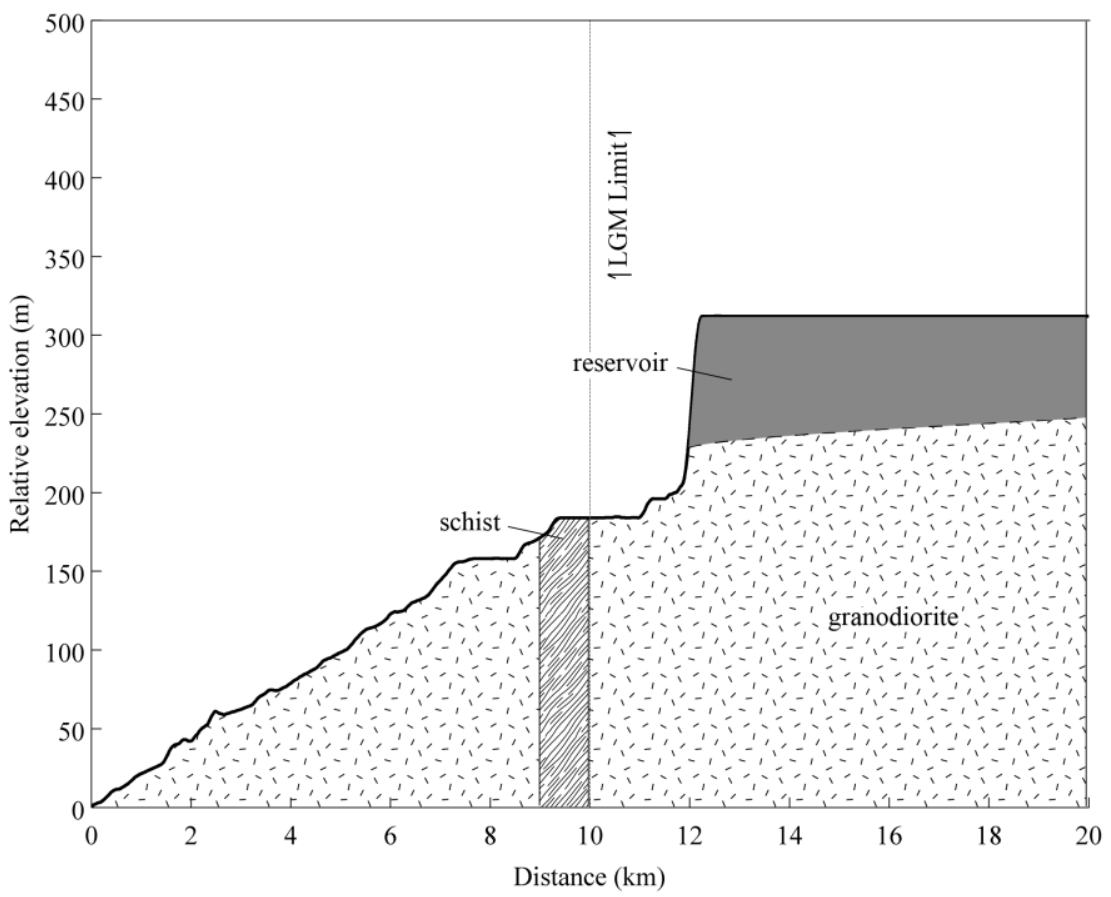

Figure 7p. Longitudinal profile of San Joaquin River. 


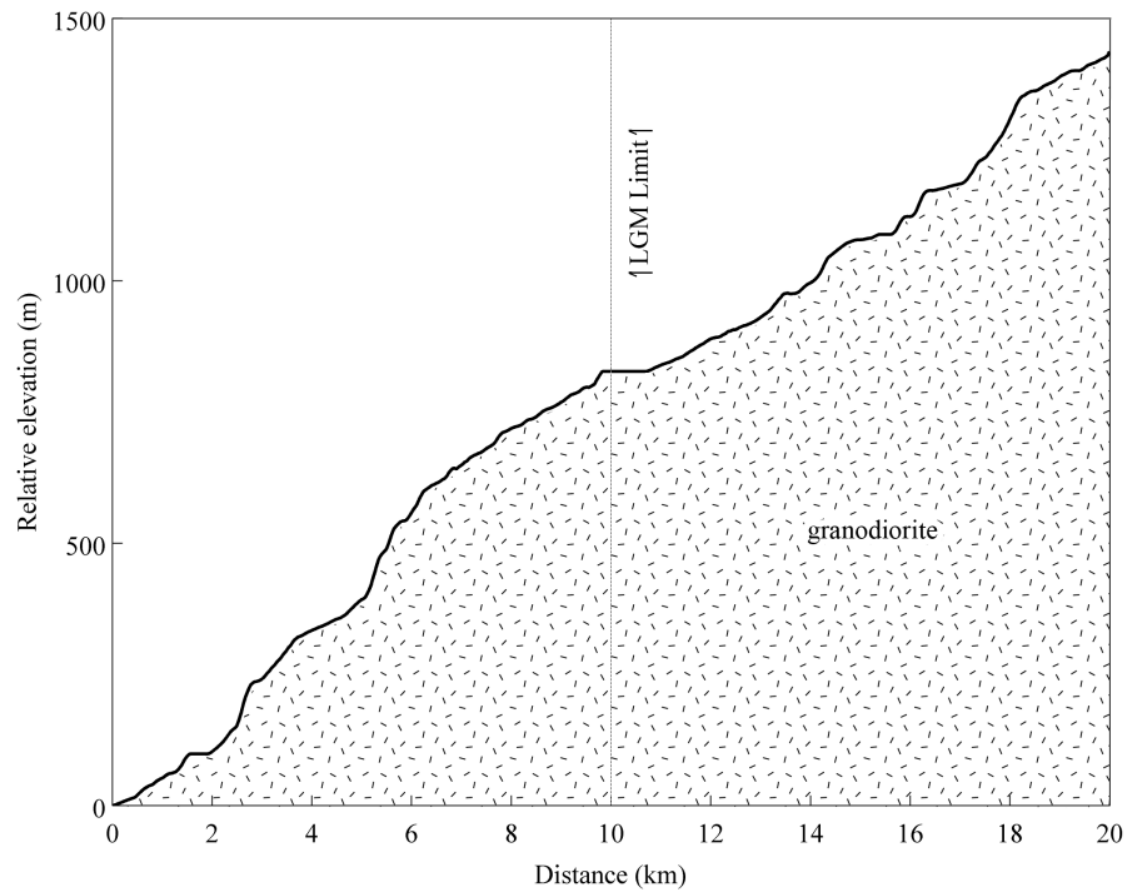

Figure 7q. Longitudinal profile of North Fork Kings River.

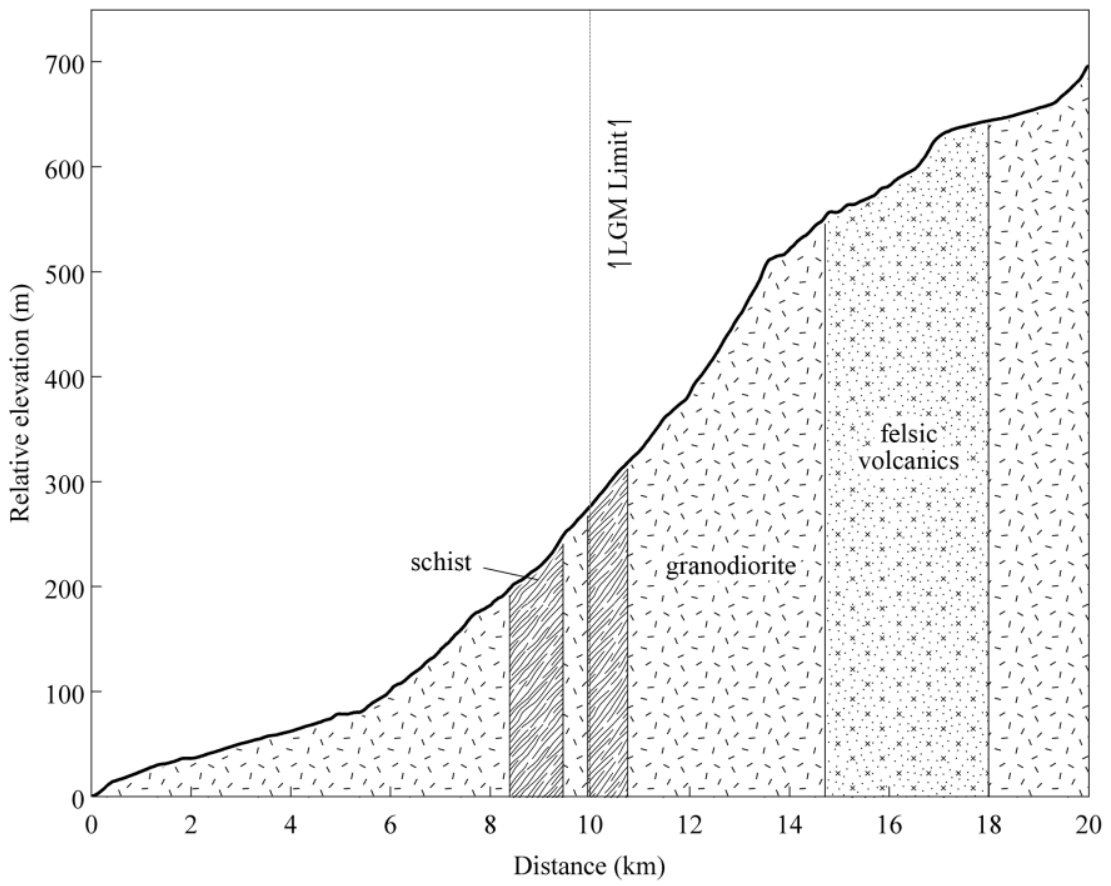

Figure 7r. Longitudinal profile of Middle Fork Kings River. 


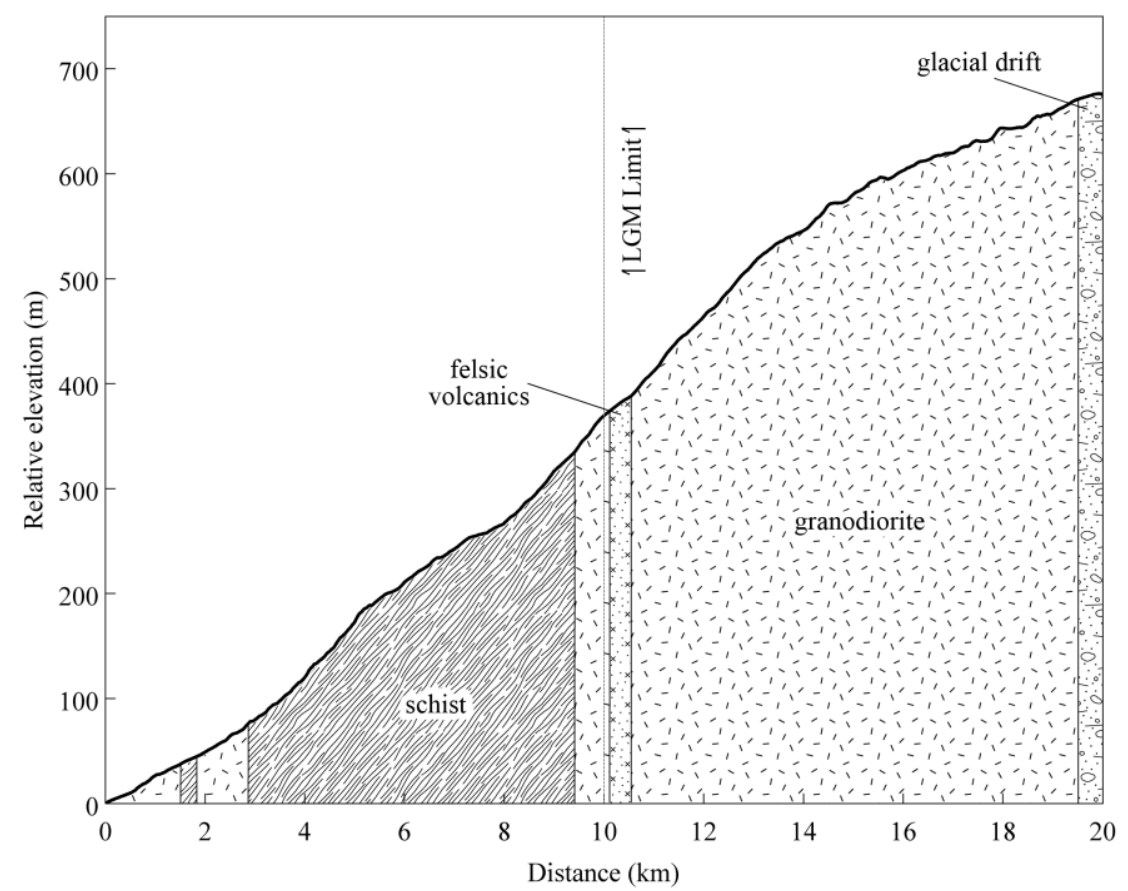

Figure 7s. Longitudinal profile of South Fork Kings River.

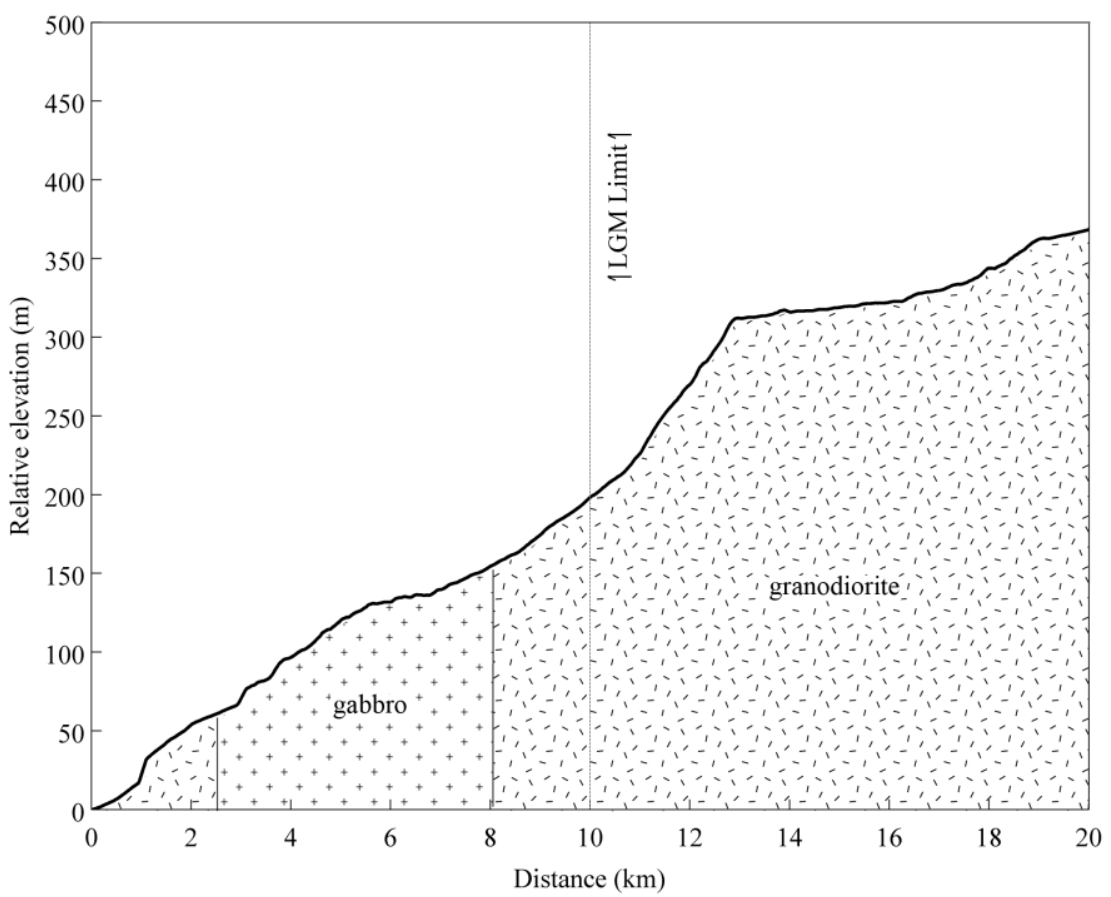

Figure 7t. Longitudinal profile of Kern River. 
The West Walker River features a prominent nickpoint in the glaciated portion of the study reach, while the Kern River also contains a distinct nickpoint $3 \mathrm{~km}$ upstream of the LGM contact. These nickpoints do not correspond to major lithological boundaries, supporting the argument provided by the cross-sectional data that rock type appears to bear little effect on range-scale morphology of glaciated streams. However, Johnson (2015) demonstrated that nickpoint formation can result from differential erosion due to textural and mineralogical variability in otherwise homogenous rock units in the Sierra Nevada; more detailed lithological analysis may provide evidence for lithological controls in the nickpoints documented in the six study reaches.

\section{DISCUSSION}

\section{Bedrock Valley Morphometry}

The results of this study indicate that the V-index is useful for quantifying valley crosssectional morphology. Unlike traditional approaches such as curve fitting, the V-index does not require symmetrical valleys (see Li et al., 2001) or smoothly sloping valley walls. Asymmetries in valley form are common in the Sierra Nevada, a phenomenon noted by Jensen (2014) and further demonstrated here by the variation in power curve fitting results often seen from either side of a single cross-section (average difference in $b$-exponent $=$ $0.253 ; 1 \sigma=0.283)$. Further, a large number of valleys are convex $(\mathrm{V}$-indices $<0)$ owing primarily to irregular walls with large bedrock protrusions (see Figure 3). These irregularities introduce error into curve fitting approaches that are based on ideal forms. The $\mathrm{V}$-index provides a fast and reliable method for quantifying the distribution of cross-sectional 
form of valleys of varying orders of magnitude in depth and width, and it is supported by logistic regression analysis. Figure 8 shows the distribution of V-indices in the study area.

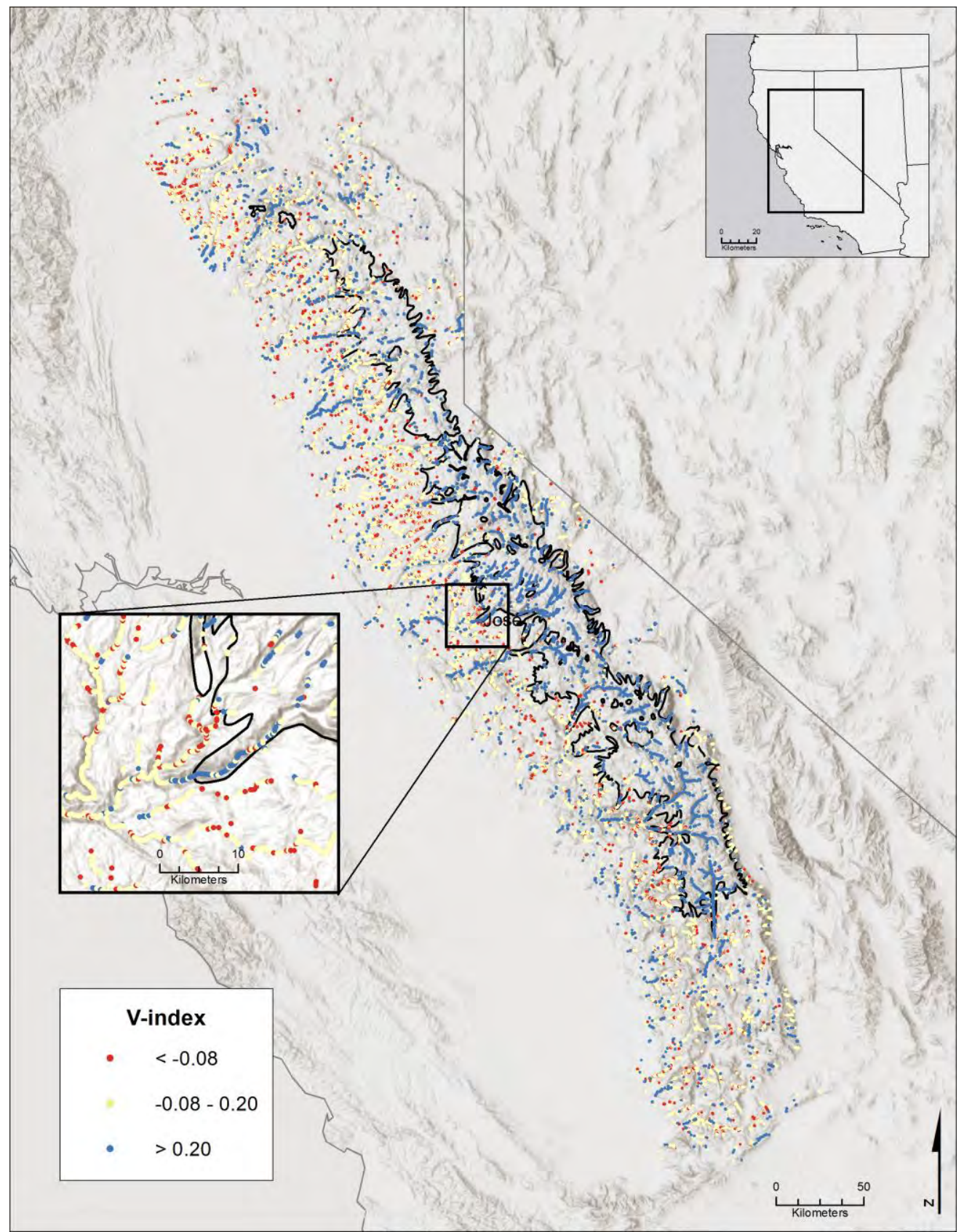

Figure 8. Distribution of V-indices. Black outline indicates LGM extent (Gillespie and Clark, 2011). Inset is a detail showing distinct difference in cross-sectional morphology in adjacent unglaciated and glaciated drainages within the Tuolumne River watershed. 
Further, the V-index reveals a distinct morphological difference between glaciated valleys in the northern Sierra Nevada and the southern Sierra Nevada (Table 6). Although relief and full valley width are approximately identical for the unglaciated valleys in both north and south, glaciated valleys in the southern Sierra Nevada are more U-shaped, deeper, and wider than glaciated valleys in the northern Sierra Nevada.

Table 6. Comparative statistics for northern and southern Sierra Nevada

\begin{tabular}{llrrrr}
\hline \hline & & & Valley & Full Valley \\
Region & Glaciation & V-index & Relief $(\mathrm{m})$ & Width $(\mathrm{m})$ & Elevation $(\mathrm{m})$ \\
\hline Northern Sierra & Unglaciated & 0.057 & 206 & 1,162 & 919 \\
Nevada & Glaciated & 0.177 & 246 & 1,355 & 1,915 \\
Southern Sierra & Unglaciated & 0.065 & 205 & 1,164 & 1,243 \\
Nevada & Glaciated & 0.196 & 313 & 1,402 & 2,357
\end{tabular}

This difference in valley cross-sectional form is likely attributable to the higher elevations found in the southern Sierra Nevada, where glaciation would have more sustained and where the bedrock would have accordingly been subjected to greater modification. Figure 9 shows the relationship between $\mathrm{V}$-indices and elevation and documents a positive correlation between increasing V-index and elevation in the glaciated valleys, while the unglaciated valleys show no trend. 


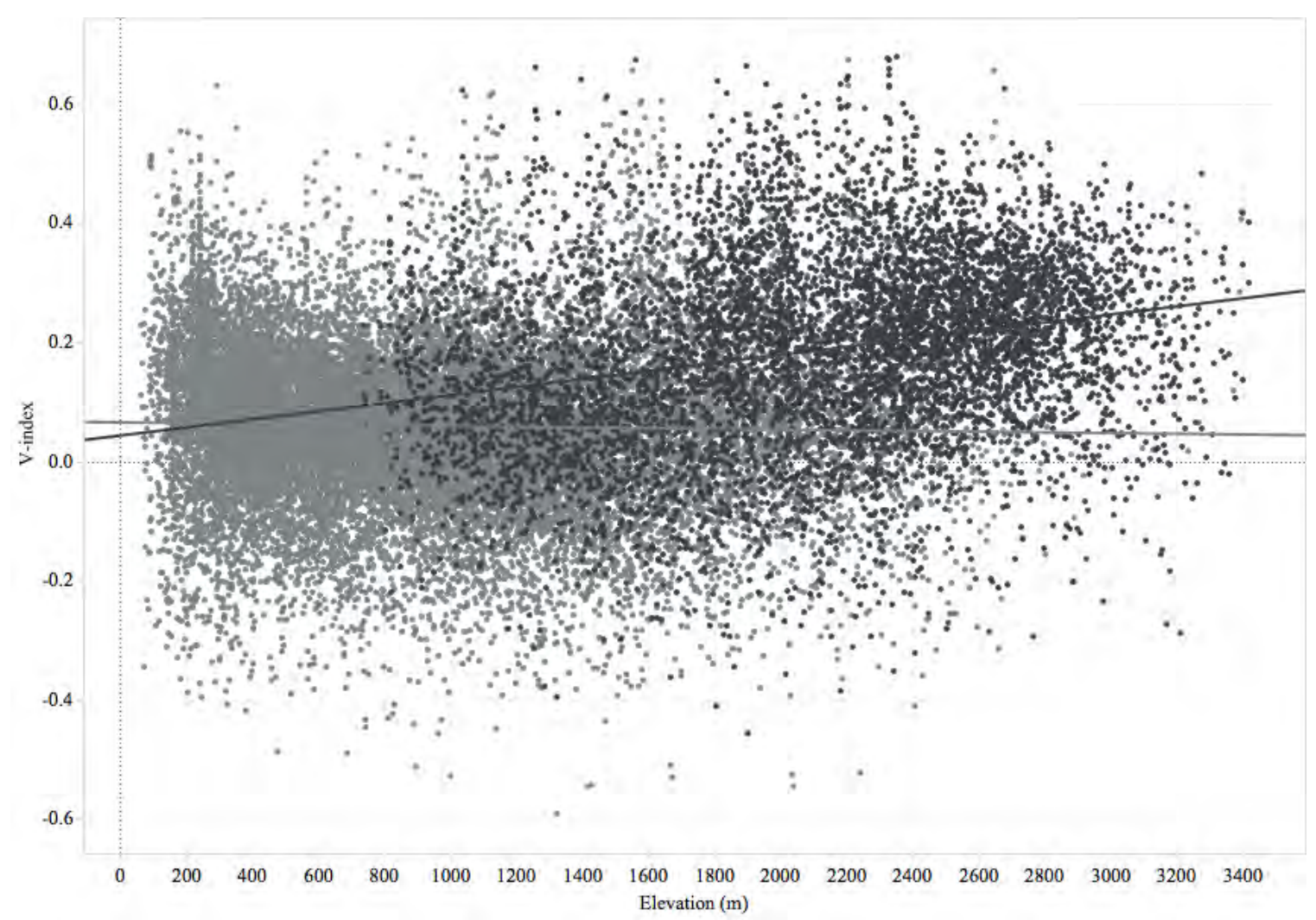

Figure 9. Relationship between V-index and elevation in study area. Glaciated valley measures and trend line shown in dark grey and unglaciated valley measures and trend shown in light grey.

This study also presents a large-scale comparative analysis between parabolic curve fitting methods, with power fitting appearing to be more discriminating than quadratic fitting for describing glacial valley shape. Svensson (1959) and Graf (1970) were the earliest proponents of the power law approach, which was supported later by the work of Hirano and Aniya (1988), among others, who argued that an ideal glacial valley shape describes a catenary curve that could be approximated by a power law. Wheeler (1984) and James (1996), in contrast, suggested that a parabolic curve described by the quadratic equation may be more appropriate for certain valley cross-sections, although this study lends support to the work of Li et al. (2001), who cautioned that the quadratic fit approach requires symmetric, 
parabolic forms and that asymmetries may produce inaccurate results. Due to the large sample size, this study employed a basic power curve fitting approach where the lowest point in each cross-section was identified as the curve origin. More rigorous power curve fitting approaches such as using a polynomial to identify the origin (Svensson, 1958) or employing alternative power law formulae (Pattyn and Van Huele, 1998) may provide more robust results for this data set.

\section{Longitudinal Profiles}

The longitudinal profile analysis revealed only minor evidence of glacial valley incision. Given the strong evidence for glacial modification of valley cross-sectional form, the long profile analysis suggests that glacial erosion in the Sierra Nevada primarily occurred through widening of pre-existing valleys rather than deepening. This finding is in keeping with the conclusions of Brocklehurst and Whipple (2002), who demonstrated that glacial modification in the eastern Sierra Nevada did not increase relief but generally enlarged drainage basin area through headward erosion into low relief surfaces.

\section{Lithological Controls}

Range-scale morphology statistics identify a signature of glacial erosion that is largely irrespective of rock type and differentiate two broad categories of valley types in the Sierra Nevada: Group 1 valleys, characterized by similar morphology in both glaciated and unglaciated reaches; and Group 2 rock-valleys, which feature distinct forms in glaciated and

unglaciated regions (Table 4). The results suggest that rocks comprising Group 1 valleys are either very resistant (glaciers had no effect on pre-existing fluvial valleys), or that the rocks are very weak and post-glacial fluvial erosion has equally modified both glaciated and 
unglaciated drainages. Group 2 rock-valleys present clear evidence of glacial modification. While it is tempting to attribute these differences to erodibility based on rock mass strength or jointing (e.g., Anderson et al., 1997), the scale of this study hampers drawing such easy conclusions, as variability in lithological units across the range precludes assigning broad determinations of rock strength. Further, the disparity in sample sizes between Group $1(n=$ $6,417)$ and Group $2(\mathrm{n}=19,964)$ may present a statistical bias toward Group 2 in range-scale statistics.

Nevertheless, considering the strong evidence for lithological controls on glacial modification in the Sierra Nevada (Dühnforth et al., 2010; Becker et al., 2015; Johnson, 2015), these results indicate that while rock strength and structure may provide localized constraints to glacial erosion in a given valley, the overall average morphology of the entire valley suggests that glacial modification occurs independent of lithology at the range scale.

\section{Semi-Automated Valley Analysis}

Advances in computing power, data procurement, and distribution are increasingly being harnessed to process large quantities of geospatial data in the geosciences. These techniques generally rely on automated or semi-automated procedures for identifying target landforms or attributes (i.e., valley shoulders, hypsometry, etc.) and subsequent calculations and classifications. Few studies have assessed glacial modification at the range scale (Coles, 2014; Allred and Luo, 2016), as most research typically focuses on individual basins or watersheds. This study produced a bedrock valley cross-sectional dataset that is three orders of magnitude larger than that presented in previously published research in the Sierra 
Nevada, a feat made possible through the use of largely unsupervised data processing using custom scripts in MATLAB and ArcMap.

This semi-automated approach used for this study relies on a MATLAB script (see Appendix) to accurately identify and isolate the central valley in each $2 \mathrm{~km}$ long crosssection. While this method allows for processing a large number of cross-sections quickly, the script cannot necessarily identify "problem" cross-sections, such as those located at the confluence of multiple streams or valleys with significant alluvium or standing water. Rather, these locations were identified manually in ArcMap in a process aided by outlier values (e.g., V-indices greater than 0.8 or shape ratios greater than 10). Although the script was calibrated using artificial cross-sections with known morphometry measures, given the inherent errors associated with automated approaches and manual culling, it is reasonable to assume some amount of error in the values used in this study. These inconsistencies appear to be rare based on random sampling and, given the very large sample size, likely have little effect on the results.

Further, considering the importance of rockfall in the Sierra Nevada (Collins and Stock, 2016) and large talus deposits that have accumulated since glacial retreat (such as Rockslides in Yosemite Valley), it is necessary to consider their effect on cross-sectional morphology in this study. Although the semi-automated method employed cannot distinguish between talus slopes and bare bedrock in individual cross-sections, the effect is likely inconsequential when averaged across the range. As rockfall is more likely in steep-walled U-shaped valleys, talus piles would accumulate in the corners of U-shaped valleys, reducing cross-sectional area and producing a more V-shaped profile. Further, V-shaped valleys are theoretically at slope 
equilibrium; therefore, rockfall should be minimal in those areas. Given that the range average is slightly more $\mathrm{U}$-shaped than $\mathrm{V}$, this study may under-represent $\mathrm{U}$-shaped valleys if the rockfall deposits are significant across the range.

\section{Glacial Mapping Accuracy}

The LGM limit used for this analysis (Gillespie and Clark, 2011) is a synthesis of previously conducted glacial mapping studies, including the work of Wahrhaftig and Birman (1965), itself a compilation of previous research. Although the methodology used to determine glaciation is typically made explicit in the source materials (i.e., presence of moraines or erratics), in some cases glacial limits were determined "from study of 1:62,5000 topographic maps" (Wahrhaftig and Birman, 1965, p. 302). That ambiguity suggests that certain valleys could have been mapped on the basis of morphology alone, in which case the arguments presented here based on the morphometric analysis may become circular. That is, if a location was mapped as glaciated strictly because it was more U-shaped than adjacent valleys, then we may simply be stating the reverse in those cases: considering that the valley is U-shaped based on shape metrics and has been mapped as glaciated, glacial modification must have occurred. As with talus piles, however, those cases are likely rare and inconsequential given the sample size.

\section{Implications for Sierran Orogeny}

This study demonstrates that while glacial erosion had a significant, measurable effect at the range scale, valley form varies widely in both glaciated and unglaciated reaches, with Vshaped and U-shaped valleys common in both. Models supporting recent uplift of the Sierra Nevada require extensive bedrock incision in order to create the current relief observed in the 
range; however, the results presented here suggest that glacial modification of bedrock valleys primarily occurs through valley widening, in keeping with other studies (e.g., Brocklehurst and Whipple, 2000). These findings suggest that glacial erosion alone was likely not responsible for the topographic relief found throughout the Sierra Nevada today, but that alpine glaciers flowed down pre-existing fluvial valleys that were already deeply incised by the Quaternary.

\section{CONCLUSIONS}

An analysis of bedrock valley cross-sections and longitudinal profiles in the Sierra Nevada, California documents a significant correlation between valley cross-sectional form and glaciation, providing strong evidence for glacial modification of pre-existing fluvial valleys. Range-scale morphology measures and longitudinal profiles suggest lithology presents only local controls on bedrock modification. A novel form metric, the V-index, is proposed as a viable alternative to other glacial morphometry measures. 


\section{REFERENCES}

Allred, K.J. and Luo, W., 2016, Data-mining based detection of glaciers: quantifying the extent of alpine valley glaciation: AIMS Geosciences, v.1(1), p. 1-18.

Anderson, R. S., Molnar, P., and Kessler, M. A., 2006, Features of glacial valley profiles simply explained: Journal of Geophysical Research, v. 111(F01004), p. 1-14.

Aniya, M. and Welch, R., Morphometric analyses of Antarctic cirques from photogrammetric measurements: Geografiska Annaler. Series A, Physical Geography, v. 63(1/2), p. 4153.

Augustinus, P. C., 1995, Glacial valley cross-profile development: the influence of in situ rock stress and rock mass strength, with examples from the Southern Alps, New Zealand: Geomorphology, v. 14, p. 87-97.

Becker, R.A., Tikoff, B., Riley, P.R., and Iverson, N.R., 2014, Preexisting fractures and the formation of an iconic American landscape: Tuolumne Meadows, Yosemite National Park, USA: GSA Today, v. 24(11), p. 4-10.

Bennett, M.M., and Glasser, N.F., 2003, Glacial Geology: Ice Sheets and Landforms: WileyBlackwell, Chichester, $400 \mathrm{p}$.

Brocklehurst, S. and Whipple, K., 2000, Glacial erosion and relief production in the Eastern Sierra Nevada, California: Geomorphology, v. 42, p. 1-24.

Brook, M.S., Kirkbride, M.P., and Brock, B.W., 2004, Rock strength and development of glacial valley morphology in the Scottish Highlands and northwest Iceland: Geografiska Annaler, v. 86, p. 225-234.

Bull, W.B. and McFadden, L.D, 1977, Tectonic geomorphology north and south of Garlock fault, California, in Doehring, D.O, ed., Geomorphology in Arid Regions: Binghamton: State University N.Y., p. 115-138.

Cassel, E. J., and Graham, S. A., 2011, Paleovalley morphology and fluvial systems evolution of Eocene-Oligocene sediments ("auriferous gravels"), northern Sierra Nevada, California: Implications for climate, tectonics, and topography: Geological Society of America Bulletin, v. 123, p. 1699-1719.

Cassel, E.J., Breecker, D.O., Henry, C.D., Larson, T.E., and Stock, D.F., 2014, Profile of a paleo-orogen: High topography across the present-day Basin and Range from 40 to 23 Ma: Geology, v. 42(11), p. 1007-1010. 
Cassel, E.J., Graham, S.A., and Chamberlain, C.P., 2009a, Cenozoic tectonic and topographic evolution of the northern Sierra Nevada, California, through stable isotope paleoaltimetry in volcanic glass: Geology, v. 37(6), p. 547-550.

Cassel, E.J., Calvert, A., and Graham, S.A., 2009b, Age, geochemical composition, and distribution of Oligocene ignimbrites in the northern Sierra Nevada, California: Implications for landscape morphology, elevation, and drainage divide geography of the Nevadaplano: International Geology Review, v. 51(7), p. 723-742.

Cassel, E.J., Graham, S.A., and Chamberlain, C.P., and Henry, C.D., 2012, Early Cenozoic topography, morphology, and tectonics of the northern Sierra Nevada and western Basin and Range: Geosphere, v. 8, p. 229-249.

Cecil, M. R., 2006, Cenozoic exhumation of the northern Sierra Nevada, California, from (UTh)/He thermochronology: Geological Society of America Bulletin, v. 118, p. 14811488.

Coles, R.J., 2014, The cross-sectional character of glacial valleys and their spatial variability [Ph.D. thesis]: Sheffield, University of Sheffield, 335 p.

Collins, B. and Stock, G.M., 2016, Rockfall triggering by cyclic thermal stressing of exfoliation fractures: Nature Geoscience, v. 9(5), p. 395-400.

Dahal, R.K., Hasegawa, S., Nonomura, A., Yamanaka, M., and Dhakal, S., 2008, DEMbased deterministic landslide hazard analysis in the Lesser Himalaya of Nepal: Georisk: Assessment and Management of Risk for Engineered Systems and Geohazards, v. 2(3), p. 161-178.

Dühnforth, M., et al., 2010, Bedrock fracture control of glacial erosion processes and rates: Geology, v. 38, p. 423-426.

Gabet, E.J., 2014, Late Cenozoic uplift of the Sierra Nevada? A critical analysis of the geomorphic evidence: American Journal of Science, v. 314, p. 1224-1257.

Gillespie, A.R. and Clark, D.H., 2011, Glaciations of the Sierra Nevada, California, USA in Ehlers, J., Gibbard, P.L., and Hughes, P.D., eds., Quaternary Glaciations - Extent and Chronology: A Closer Look, Developments in Quaternary Science, v. 15, Elsevier, $1108 \mathrm{p}$.

Graf, W.L., 1970, The geomorphology of the glacial valley cross-section: Arctic and Alpine Research, v. 2, p. 303-312. 
Hallet, B., Hunter, L., and Bogen, J., 1996, Rates of erosion and sediment evacuation by glaciers: A review of field data and their implications: Global and Planetary Change, v. 12 , p. 213-235.

Harbor, J. M., 1990, A discussion of Hirano and Aniya's $(1988,1989)$ explanation of glacialvalley cross profile development: Earth Surface Processes and Landforms, v. 15, p. 369-377.

Harbor, J.M., 1992, Numerical modeling of the development of U-shaped valleys by glacial erosion: Geological Society Bulletin, v. 104, p. 1364-1375.

Harbor, J., and Warburton, J., 1993, Relative rates of glacial and nonglacial erosion in alpine environments: Artic and Alpine Research, v. 25, p. 1-7.

Hebdon, N.J., Atkinson, T.C., Lawson, T.J., and Young, I.R., 1997, Rate of glacial valley deepening during the late Quaternary in Assynt, Scotland: Earth Surface Processes and Landforms, v. 22, p. 307-315.

Henry, C.D., 2008, Ash-flow tuffs and paleovalleys in northeastern Nevada: Implications for Eocene paleogeography and extension in the Sevier hinterland, northern Great Basin: Geosphere, v. 4(1), p. 1-35.

Henry, C. D., Hinz, N. H., Faulds, J. E., Colgan, J. P., John, D. A., Brooks, E. R., Cassel, E. J., Garside, L. J., Davis, D. A., and Castor, S. B., 2012, Eocene-Early Miocene paleotopography of the Sierra Nevada-Great Basin-Nevadaplano based on widespread ash-flow tuffs and paleovalleys: Geosphere, v. 8(1), p. 1-27.

Hicks, D.M., McSaveney, M.J., and Chinn, T.J.H., 1990, Sedimentation in proglacial Ivory Lake, Southern Alps, New Zealand: Arctic and Alpine Research, v. 22, p. 26-42.

Hirano, M. and Aniya, M., 1988, A rational explanation of cross-profile morphology for glacial valleys and of glacial valley development: Earth Surface and Processes, v. 13, p. 707-716.

Hoek, E. and Brown, E.T., 1997, Practical estimates of rock mass strength: International Journal of Rock Mechanics and Mining Sciences, v. 34(8), p. 1165-1186.

Huber, N.K., 1981, Amount and timing of Late Cenozoic uplift and tilt on the central Sierra Nevada, California - Evidence from the upper San Joaquin River basin: US Geological Survey Professional Paper 1197, 28 p. 
Irwin, William P., and Wooden, Joseph L., 2001, Map showing plutons and accreted terranes of the Sierra Nevada, California with a tabulation of U/Pb isotopic ages: U.S. Geological Survey Open-File Report 01-229, http://pubs.usgs.gov/of/2001/0229/.

James, L.A., 1996, Polynomial and Power Functions for Glacial Valley Cross-section Morphology: Earth Surface Processes and Landforms, v. 21, p. 413-432.

Jensen, K., 2014, The role of lithology in glacial valley cross-sectional shape in Sierra Nevada, California: [Master's thesis], San Jose, San Jose State University, 170 p.

Johnson, A. M., 1970, Physical Processes in Geology; a method for interpretation of natural phenomena; intrusions in igneous rocks, fractures and folds, flow of debris and ice, Freeman Cooper and Co., San Francisco, 577 pp.

Johnson, B.D., 2015, Lithologic controls on knickpoint formation in Sierra Nevada bedrock channels: [Master's thesis], San Jose, San Jose State University, 71 p.

Leith, K., Moore, J. R., Amman, F., and Loew, S., 2014, Subglacial extensional fracture development and implications for Alpine Valley evolution, Journal of Geophysical Research: Earth Surface, v. 19, p. 62-81.

Li, Y., Liu, G., and Cui, Z. 2001, Glacial valley cross-profile morphology, Tian Shan Mountains, China: Geomorphology, v. 38, p. 153-166.

Liang, F., and Xu, B., 2014, Discrimination of tower-, cockpit-, and non-karst landforms in Guilin, Southern China, based on morphometric characteristics: Geomorphology, v. 204, p. 42-48.

Lindgren, W., 1911, The Tertiary gravels of the Sierra Nevada of California: U.S.G.S. Professional Paper 73, 226 p.

Martel, S. J., Stock, G. M., and Ito, G., 2014, Mechanics of relative and absolute displacements across normal faults, and implications for uplift and subsidence along the eastern escarpment of the Sierra Nevada, California: Geosphere, v. 10(2), p. 243263.

Matthes, F.E., 1930, Geologic History of the Yosemite Valley: U.S. Geologic Survey Professional Paper 160, 131 pp.

Matthes, F.E., and Fryxel, F., 1950, The Incomparable Valley. A Geologic Interpretation of the Yosemite: University of California Press, Berkeley, 173 p. 
Menard, S.W., 2002, Applied Logistic Regression Analysis: Sage University Paper Series on Quantitative Applications in the Social Science 07-106, Sage Publications, Thousand Oaks, 128 p.

Mix, H.T., Ibarra, D.E., Mulch, A., Graham, S.A., and Chamberlain, C.P., 2015, A hot and high Eocene Sierra Nevada, Geological Society of America Bulletin, v. 128(3-4), p. $531-542$.

Montgomery, D.R., 2002, Valley formation by fluvial and glacial erosion: Geology, v. 30, p. $1047-1050$.

Montgomery, D.R., 2003, Predicting landscape-scale erosion rates using digital elevation models: Comptes Rendus Geosciences, v. 335, p. 1121-1130.

Nagelkerke, N.J.D., 1991, A Note on a General Definition of the Coefficient of Determination: Biometrika, v. 78(3), p. 691-692.

Naylor, S. and Gabet, E.J., 2006, Valley asymmetry and glacial versus nonglacial erosion in the Bitterroot Range, Montana, USA: Geology, v. 35(4), p. 374-378.

Pattyn, Frank and Van Huele, Wim, 1998, Power law or power flaw?: Earth Surface Processes and Landforms, v. 23, p. 761-767.

Pazzaglia, F.J., Gardner, T.W., and Merritts, D.J., 1998, Bedrock fluvial incision and longitudinal profile development over geologic time scales determined by fluvial terraces in Tinkler, J. and Wohl, E., eds., Rivers Over Rock: Fluvial Processes in Bedrock Channels: American Geophysical Union, Washington, D.C., Geophysical Monograph Series., v. 107, p. 207-235.

Pike, R.J., Evans, I.S., and Hengl, T., 2008, Geomorphometry: a Brief Guide in Hengl, T. and Reuter, H.I., eds., Geomorphometry: Geomorphometry: Concepts, Software, Applications, Developments in Soil Science, v. 33, Elsevier, 1-28 p.

Plummer, C.C., Carlson, D.H., McGeary, D., 2007, Physical Geology: McGraw Hill, New York, $704 \mathrm{p}$.

Pohar, M., Blas, M., and Turk, S., 2004, Comparison of logistic regression and linear discriminant analysis: a simulation study: Metodoloski Zvezki, v.1(1), p. 143-161.

Ritter, D. F., Kochel, R. C., and Miller, J. R., 2011, Process Geomorphology, Waveland Press, $652 \mathrm{p}$. 
Rogers, C.M. and Engelder, T., 2004, The feedback between joint-zone development and downward erosion of regularly spaced canyons in the Navajo Sandstone, Zion National Park, Utah: Geological Society, London, Special Publications 2004, v. 231, p. $49-71$.

Russell, I. C., 1889, Quaternary history of Mono Valley, California in 8th Annual Report of the United States Geological Survey, 1886-87, Pt. 1., Government Printing Office, Washington, D.C., p. 261-394.

Schumm, S.A. and Ethridge, F.G., 1994, Origin, evolution, and morphology of fluvial valleys in Dalrymple, R.W., Boyd, R.J., and Zaitlin, B.A., eds, Incised-valley Systems: Origin and Sedimentary Sequences, SEPM Special Publication No. 51, p. 13-27.

Shean, D.E., Head, J.W., Fastook, J.L, and Marchant, D.R., 2007, Recent glaciation at high elevations on Arsia Mons, Mars: Implications for the formation and evolution of large tropical mountain glaciers: Journal of Geophysical Research, v. 112 (E03004), 23 p.

Svensson, H., 1959, Is the cross-section of a glacial valley a parabola?: Journal of Glaciology, v. 3, p. 362-363.

Tchoukansi, Ianko, 2016, ET Geowizards: A data analysis add-on package for ArcGIS software: ET Spatial Techniques, Pretoria, South Africa, http://www.ian-ko.com/.

U.S. Geological Survey, 2007, California geologic map data: https://mrdata.usgs.gov/geology/state/state.php?state=CA (accessed January 2016).

U. S. Geological Society, 2012, Medium resolution (1:100,000 scale) National Hydrography Dataset stream network data: http://nhd.usgs.gov/ (accessed January 2016).

Wahrhaftig, C., 1965, Stepped topography of the southern Sierra Nevada, California: Geological Society of America Bulletin, v. 76, p. 1165-1190.

Wahrhaftig C. and Birman, J.H., 1965, The Quaternary of the Pacific mountain system in California in Wright, H.E. and Frey, D.G., The Quaternary of the United States: Princeton University Press, Princeton, p. 299-304.

Wakabayashi, J., 2013, Paleochannels, stream incision, erosion, topographic evolution, and alternative explanations of paleoaltimetry, Sierra Nevada, California: Geosphere, v. 9 (2), p. $1-25$. 
Wakabayashi, J., and Sawyer, T.L., 2001, Stream incision, tectonics, uplift and evolution of topography of the Sierra Nevada, California: The Journal of Geology, v. 109, p. 539562.

Wheeler, D.A., 1984, Using parabolas to describe the cros-sections of glaciated valleys, Earth Surface Processes and Landforms, v. 9, p. 391-394. 


\section{APPENDIX A: MATLAB Script}

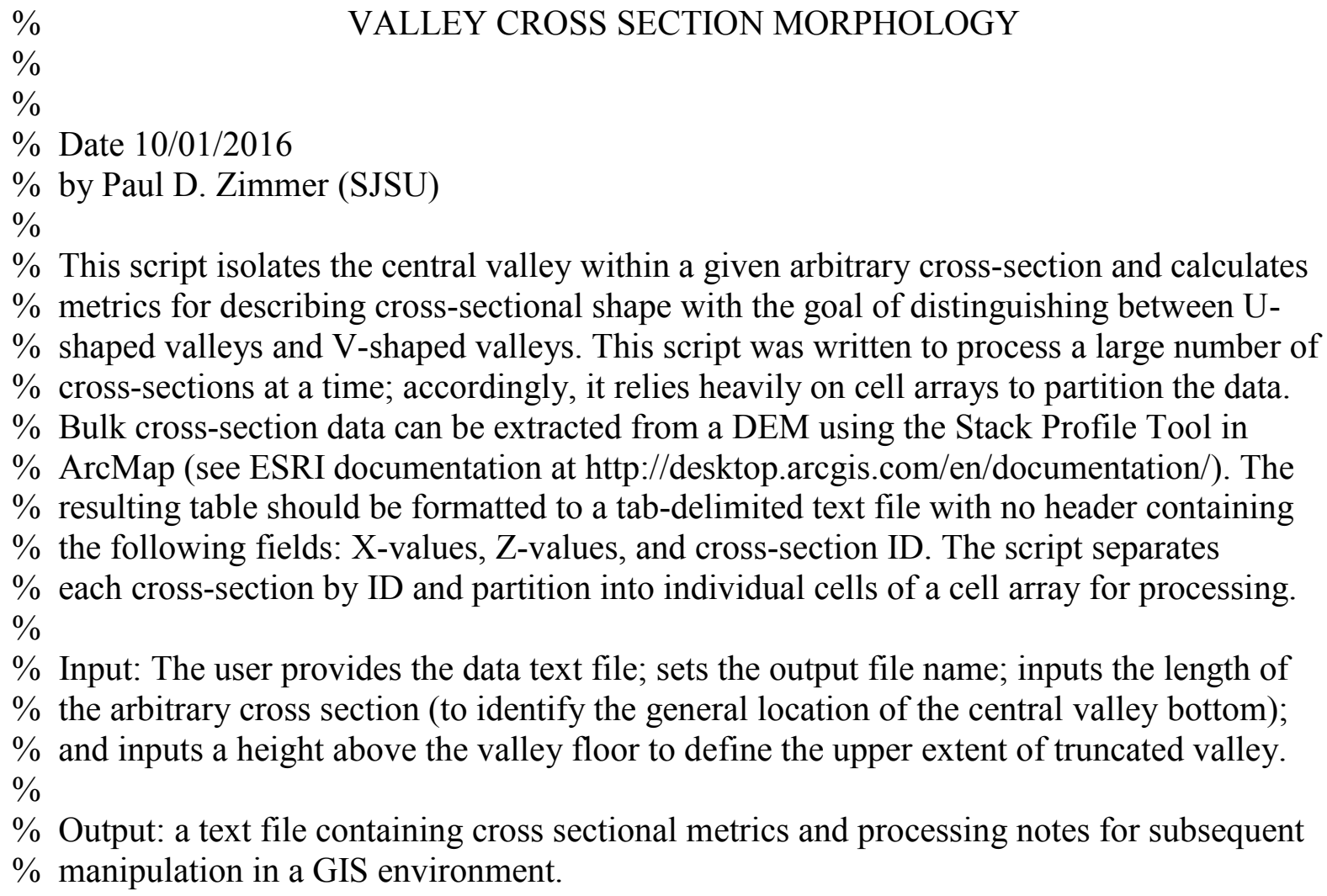

\section{\% 1. IMPORT CROSS-SECTION DATA}

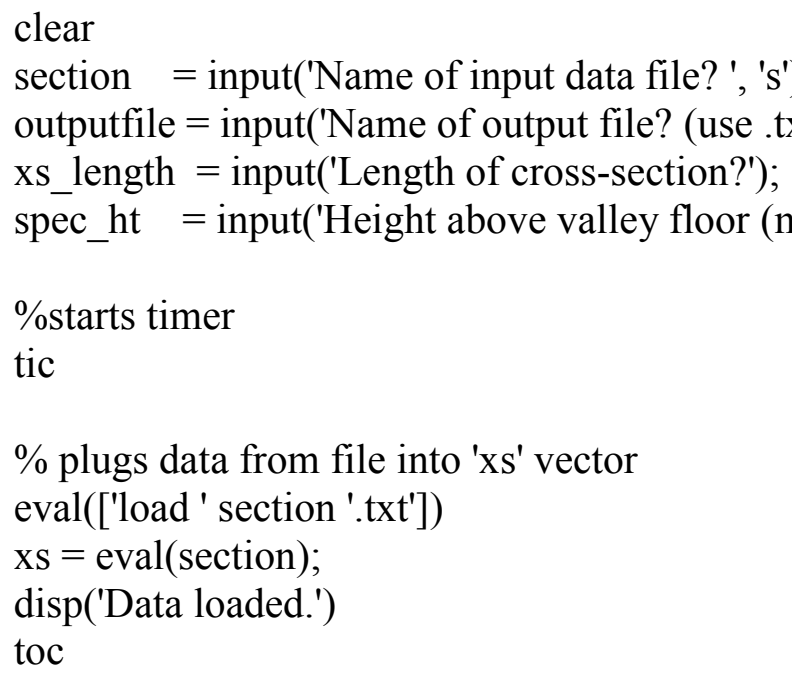




\section{$\%$ 2. SEPARATE CROSS-SECTIONS INTO INDIVIDUAL CELLS OF CELL ARRAY}

$\%$ spilts cross-section data by Line_ID into separate cells

xs_array=arrayfun $(@(x) x s(x s(:, 3)==x,:)$, unique $(x s(:, 3))$, 'uni', false $)$;

$\%$ creates array of cross section identifiers

Line_ID=cellfun(@(x) unique $(\mathrm{x}(:, 3))$, xs_array, 'uni', false $)$;

$\%$ creates new $\mathrm{x}$ vector with 1 meter intervals

x_int = cellfun(@(x) transpose $(x(1,:): 1: x(e n d,:))$, xs_array, 'uni', false $)$;

$\%$ interpolates $z$ values to length of $\mathrm{x} \_$int

z_int=cellfun(@(x,y) transpose $($ interp1 $(x(:, 1), x(:, 2), 1:$ length(y) ,'linear')), xs_array,... x_int, 'uni', false);

$\%$ recombines $\mathrm{x}$ and $\mathrm{z}$ data into one cell per cross-section

xs_int=cellfun(@(x,y) cat $(2, x, y), x \_$int, z_int, 'uni', false $)$;

$\%$ replaces undefined $z$-value at end of each column with value from original data for $\mathrm{i}=1$ :length(xs_int)

xs_int $\{i\}($ end, 2$)=x s \_$array $\{i\}($ end, 2$)$;

end

disp('Cell array created.')

toc

\section{\% 3. EXTRACT MAIN VALLEY FROM EACH CROSS-SECTION}

$\%$ sets value for center of cross-section

xs_center $=$ double $(\operatorname{int} 16(0.5 *$ xs_length $))$;

$\%$ finds location of peaks - NOTE: requires Signal Processing Toolbox

[pks, pk_locs]=cellfun(@(x) findpeaks(x(:,2)), xs_int, 'uni', false);

$\%$ finds location of valleys by inverting XS and locating "peaks"

[minima, min_locs] = cellfun(@(x) findpeaks $(-(x(:, 2)))$, xs_int, 'uni', false);

$\%$ recasts minima values as positive

minima = cellfun $(@(x)-x$, minima, 'uni',false $)$; 
$\%$ finds location of valley bottom closest to center of cross-section

[center, center_idx]=cellfun(@(x) min(abs(x(:) - xs_center $))$, min_locs,'uni', false $)$;

valmin_loc=cellfun $(@(\mathrm{x}, \mathrm{y}) \mathrm{x}(\mathrm{y})$, min_locs, center_idx, 'uni', false $)$;

valmin_elev=cellfun $\left(@(x, y) x(y, 2), x s \_i n t\right.$, valmin_loc, 'uni', false $)$;

for $\mathrm{i}=1$ :length(valmin_loc)

if isempty(valmin_loc $\{\mathrm{i}\}) \|$ valmin_loc $\{\mathrm{i}\}==0$

valmin_loc $\{i\}=x$ s_center;

valmin_elev $\{i\}=x s \_$int $\{i\}($ valmin_loc $\{i\}, 2)$;

end

end

$\%$ identifies peak locations on left side of valley

left_peaks=cellfun $(@(x, y)$ flip $(x(x<y))$, pk_locs, valmin_loc, 'uni', false $)$;

$\%$ sets leftmost $\mathrm{x}$-value as a "peak"

left_peaks=cellfun(@(x) [x;1], left_peaks, 'uni', false);

$\%$ sets peak closest to valley bottom as the first peak to check; finds peak elevation

left_peak=cellfun(@(x)x(1), left_peaks, 'uni', false);

left_elev=cellfun(@(x,y)x(y,2),xs_int, left_peak, 'uni', false $)$;

$\%$ sets locations of cross section left-side minima

left_min_locs=cellfun(@(x,y) flip $(x(x<y))$, min_locs, valmin_loc, 'uni',false $)$;

$\%$ checks that calculated peak is not a minor rise $(<10 \mathrm{~m})$ on valley wall

left_rise=cellfun(@(x) $x^{*} 0$, valmin_loc, 'uni', false); \%initialize value to 0

for $\mathrm{i}=1$ :length(left_peak)

check $=0$;

if length(left_peaks $\{\mathrm{i}\})>1$

for $\mathrm{j}=1$ :length(left_min_locs $\{\mathrm{i}\})$

if check $==0 \& \&\left(\right.$ left_elev $\{i\}-x s \_$int $\{i\}(($ left_min_locs $\left.\{i\}(j)), 2)<10\right) \& \& \ldots$

(left_elev $\{\mathrm{i}\}<($ xs_int $\{\mathrm{i}\}(\bar{l}$ left_peaks $\{\mathrm{i}\}(\mathrm{j}+1), 2)))$

left_peak $\{\mathrm{i}\}=$ left_peaks $\{\mathrm{i}\}(\overrightarrow{\mathrm{j}+1)}$;

left_elev $\{i\}=x s$ int $\{i\}($ left_peak $\{i\}, 2)$;

left_rise $\{\mathrm{i}\}=\mathrm{j}$;

else check $=1$;

break

end

end

end

end 
$\%$ calculates max relief of left-side valley

left_relief=cellfun $(@(x, y) x-y$, left_elev, valmin_elev, 'uni', false $)$;

$\%$ identifies peak locations to right of valley bottom

rt_peaks=cellfun $@(x, y) x(x>y), p k \_l o c s$, valmin_loc, 'uni', false $)$;

$\%$ sets rightmost $\mathrm{x}$-value as a "peak"

rt_peaks=cellfun(@(x,y) [x;(y(end,1))], rt_peaks, xs_int, 'uni', false $)$;

$\%$ sets peak closest to valley bottom as the first peak to check; finds peak elevation rt_peak=cellfun(@(x)x(1),rt_peaks, 'uni', false);

rt_elev=cellfun(@(x,y) x(y,2),xs_int, rt_peak, 'uni', false);

$\%$ sets locations of cross section right-side minima

rt_min_locs=cellfun(@(x,y) x(x>y), min_locs, valmin_loc, 'uni',false $)$;

$\%$ checks that calculated peak is not a minor rise $(<10 \mathrm{~m})$ on valley wall

rt_rise=cellfun(@(x) $x^{*} 0$, valmin_loc, 'uni', false); \%initialize value to 0

for $\mathrm{i}=1:$ length(rt_peak)

check $=0$;

if length(rt_peaks $\{\mathrm{i}\})>1$

for $\mathrm{j}=1$ :length(rt_min_locs $\{\mathrm{i}\}$ )

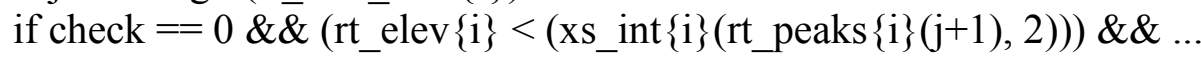 $\left(\right.$ rt_elev $\{\mathrm{i}\}$ - xs_int $\{\bar{i}\}\left(\left(\mathrm{rt} \_\min \_\right.\right.$locs $\left.\left.\left.\{\mathrm{i}\}(\mathrm{j})\right), 2\right)<10\right)$

rt peak $\{\mathrm{i}\}=$ rt_peaks $\{\mathrm{i}\} \overline{\mathrm{j}}+1)$;

rt_rise $\{\mathrm{i}\}=\overline{\mathrm{j}}$;

rt_elev $\{i\}=x s \_$int $\{i\}\left(r t \_p e a k\{i\}, 2\right)$;

else check $=1$;

break

end

end

end

end

$\%$ calculates max relief of right-side valley

rt_relief = cellfun(@(x,y)x-y, rt_elev, valmin_elev, 'uni', false);

$\%$ calculates minimum relief for whole valley

min_relief = cellfun(@(x,y) min([x,y]), left_relief, rt_relief, 'uni', false);

$\%$ extracts central valley of cross-section between left and right peaks 
xs_processed =cellfun(@(x,y,z) x(y:z,:),xs_int, left_peak, rt_peak,'uni', false $)$;

$\%$ clips cross section to lowest peak elevation

indices $=$ cellfun $\left(@(\mathrm{x}, \mathrm{y}, \mathrm{z}) \mathrm{x}(:, 2)<(\mathrm{y}+\mathrm{z}), \mathrm{xs} \_\right.$processed, valmin_elev, min_relief, 'uni',... false);

xs_clip=cellfun $\left(@(x, y) x(y,:), x s \_p r o c e s s e d\right.$, indices, 'uni', false $)$;

$\%$ locates empty cross sections (where lowest peak was at 0 ) and inserts flat line bad_clip=find(cell2mat(cellfun $\left(\right.$ @ $(x)$ length $(x), x s \_c l i p$, 'uni', false $\left.\left.)\right)<5\right)$;

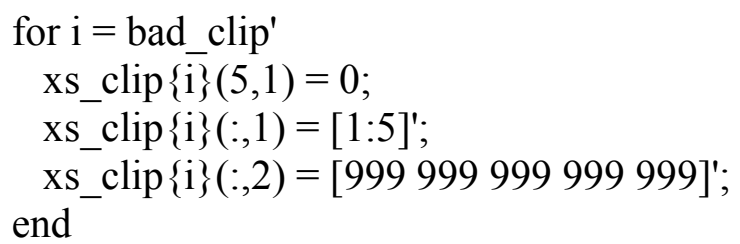

left_peak=cellfun $(@(x) \times(1,1)$, xs_clip, 'uni', false $)$;

rt_peak=cellfun(@(x)x(end,1),xs_clip, 'uni', false);

\%calculates valley width between peaks

valley_width = cellfun(@(x) $\max (\mathrm{x}(:, 1))$ - $\min (\mathrm{x}(:, 1)), \mathrm{xs}$ _clip, 'uni', false $)$;

disp('Valleys isolated.')

toc

\section{$\%$ 4. CALCULATE CROSS-SECTIONAL AREA TO SPECIFIED HEIGHT ABOVE \\ $\%$ VALLEY FLOOR}

$\%$ Calculates valley heights and corresponding elevations

spec_elev= cellfun(@(x) spec_ht + x, valmin_elev, 'uni', false);

$\%$ values for truncated valley shape ratio calculation

qt_elev=cellfun $(@(x)(.25 *$ spec_ht $)+x$, valmin_elev,'uni', false $)$;

sf_elev=cellfun (@(x) (.75* spec_ht)+x, valmin_elev, 'uni', false);

$\%$ values for full valley shape ratio calculation

qt_elev2 = cellfun $(@(\mathrm{x}, \mathrm{y})(.25 * \mathrm{y})+\mathrm{x}$, valmin_elev, min_relief, 'uni', false $)$;

sf_elev2=cellfun (@(x,y) (.75*y)+x, valmin_elev, min_relief, 'uni', false);

$\%$ isolates cross-section below specified elevation

below_spec = cellfun $(@(\mathrm{x}, \mathrm{y}) \mathrm{x}(:, 2)<=\mathrm{y}$, xs_clip, spec_elev, 'uni', false $)$;

x_below_spec $=$ cellfun $(@(x, y) x(y, 1)$, xs_clip, below_spec, 'uni', false $)$; 
z_below_spec =cellfun(@(x,y) x(y,2),xs_clip, below_spec, 'uni', false $)$;

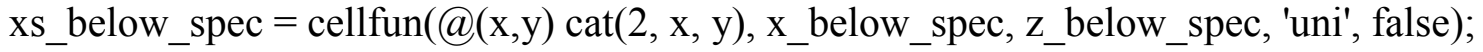

$\%$ locates empty cross sections and inserts flat line

bad_spec = find $\left(\right.$ cell2mat $\left(\operatorname{cellfun}\left(@(x)\right.\right.$ length $\left.\left.\left.(x), x s \_b e l o w \_s p e c, ~ ' u n i ', f a l s e\right)\right)<5\right)$;

for $\bar{i}=$ bad_spec'

xs_below_spec $\{\mathrm{i}\}(5,1)=0$;

xs_below_spec $\{\mathrm{i}\}(:, 1)=[1: 5]$;

xs_below_spec\{i\}(:,2)=[999 999999999 999]';

end

n_below_spec =cellfun(@(x) length(x),xs_below_spec, 'uni', false);

$\%$ calculates the area below spec_elev by numerical integration using vertical slices sum_elevs=cellfun(@(x,y) sum $(\mathrm{x}(\mathrm{y}, 2))$, xs_clip, below_spec, 'uni', false $)$;

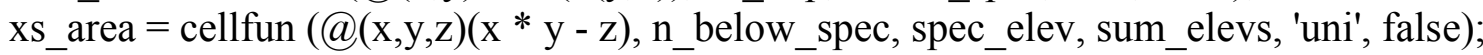

disp('Cross sectional area computed.')

toc

\section{\% 5. CALCULATE SHAPE METRICS}

$\%$ get the $\mathrm{x}$ coordinates of ends of $\mathrm{xs}$ _below_spec

x_min=cellfun(@(x)min(x(:,1)),xs_below_spec, 'uni', false); \% get the left-most x

x_max = cellfun(@(x) max (x(:,1)),xs_below_spec, 'uni', false); \% get the right-most x

$\%$ calculate the area assuming a perfect $\mathrm{V}$-shaped valley

V_area =cellfun $(@(x, y) 0.5 *(x-y) *$ spec_ht, x_max, x_min, 'uni', false $)$;

below_qt $=$ cellfun $\left(@(x, y)(x(:, 2)<=y), x s \_c l i p, q t \_e l e v\right.$, 'uni', false $)$;

below_sf = cellfun $(\mathrm{x}, \mathrm{x}, \mathrm{y})(\mathrm{x}(:, 2)<=\mathrm{y}), \mathrm{xs}$ _clip, sf_elev, 'uni', false $)$;

below_qt_x = cellfun(@(x,y) x(y,1),xs_clip, below_qt, 'uni', false);

below_sf_x = cellfun $(9(\mathrm{x}, \mathrm{y}) \mathrm{x}(\mathrm{y}, 1), \mathrm{xs}$ _clip, below_sf, 'uni', false);

qt_min=cellfun(@(x)min(x(:,1)),below_qt_x, 'uni', false); \% get left-most $\mathrm{x}$ at 25\% qt_max = cellfun(@(x) max(x(:,1)),below_qt_x, 'uni', false); \% get right-most $x$ at 25\%

sf_min=cellfun(@(x)min(x(:,1)),below_sf_x, 'uni', false); \% get left-most $x$ at $75 \%$ sf_max $=$ cellfun(@(x) max $(x(:, 1))$, below_sf__x, 'uni', false $) ; \%$ get right-most $x$ at $75 \%$ 
$\%$ values for full valley shape ratio calculation below_qt2=cellfun $\left(@(x, y)(x(:, 2)<=y), x s \_c l i p, q t \_e l e v 2\right.$, 'uni', false $)$; below_sf2=cellfun $\left(@(x, y)(x(:, 2)<=y), x s \_c l i p, s f \_e l e v 2\right.$, 'uni', false $)$;

below_qt_x2=cellfun(@(x,y) x(y,1),xs_clip, below_qt2, 'uni', false $)$; below_sf_x2=cellfun $\left(@(x, y) x(y, 1), x s \_c l i p, b e l o w \_s f 2\right.$, 'uni', false $)$;

qt_min2=cellfun $(@(x) \min (x(:, 1))$, below_qt_x2, 'uni', false $) ; \%$ get left-most x at 25\% qt_max2=cellfun(@(x) max(x(:,1)),below_qt_x2, 'uni', false); \% get right-most x at 25\%

sf_min2=cellfun(@(x) $\min (x(:, 1))$, below_sf_x2, 'uni', false $) ; \%$ get left-most x at 75\% sf_max2=cellfun(@(x) max(x(:,1)),below_sf_x2, 'uni', false); \% get right-most x at 75\%

$\% \mathrm{~V}$-index is the ratio of the cross sectional area to the area of a perfect $\mathrm{V}$ $\mathrm{V}$-index=cellfun $(@(\mathrm{x}, \mathrm{y})(\mathrm{x} / \mathrm{y})-1, \mathrm{xs}$ _area, V_area, 'uni', false $)$;

$\%$ calculates difference between cross sectional area and perfect $\mathrm{V}$ in square meters UV_area=cellfun $\left(@(x, y)(x-y), x s \_a r e a, V \_a r e a\right.$, 'uni', false $)$;

\% replaces empty $\mathrm{V}$-index values with 999

for $\mathrm{i}=1$ :length $(\mathrm{V}$-index $)$

if isempty $(\mathrm{V}$-index $\{\mathrm{i}\})$

$\mathrm{V}$-index $\{\mathrm{i}\}=999$;

end

end

$\%$ calcutates valley width at specified elevation

spec_width=cellfun(@(x,y)x-y, x_max, x_min, 'uni', false $)$;

qt_width=cellfun $\left(@(x, y) x-y, q t \_m a x, q t \_m i n\right.$, 'uni', false $)$;

sf_width=cellfun $(@(x, y) x-y$, sf_max,sf_min, 'uni', false $)$;

$\%$ values for full valley shape ratio calculation

qt_width2=cellfun $\left(@(x, y) x-y, q t \_m a x 2, q t \_m i n 2\right.$, 'uni', false $)$;

sf_width2=cellfun(@(x,y) x-y,sf_max2,sf_min2, 'uni', false);

$\%$ calculates shape ratio of truncated valley width at $75 \%$ height $/ 25 \%$ width shape_ratio=cellfun(@(x,y)x/y,sf_width, qt_width, 'uni', false $)$;

for $\mathrm{i}=1$ :length(shape_ratio)

if isempty(shape_ratio $\{\mathrm{i}\}) \|$ shape_ratio $\{\mathrm{i}\}==0$

shape_ratio $\{i\}=42$;

end 
end

$\%$ calculates shape ratio of full valley width at $75 \%$ height $/ 25 \%$ width shape_ratio2=cellfun(@(x,y)x/y,sf_width2, qt_width2, 'uni', false);

for $\mathrm{i}=1$ :length(shape_ratio2)

if isempty(shape_ratio2 $\{\mathrm{i}\}) \|$ shape_ratio $2\{\mathrm{i}\}==0$

shape_ratio $2\{i\}=42$;

end

end

disp('Shape ratios computed.')

toc

\section{\% 6. CURVE FITTING}

$\%$ Quadratic curve fit for full valley

quad_fit=cellfun(@(x) fit $(x(:, 1), x(:, 2)$, 'poly2'), xs_clip, 'uni', false $)$;

quad_coef=cellfun(@(x) coeffvalues(x), quad_fit, 'uni', false);

quad_exp=cellfun(@(x)x(1), quad_coef, 'uni', false);

disp('Full valley quadratic curve fits computed')

toc

$\%$ Quadratic curve fit for truncated valley

quad_fit2=cellfun(@(x) fit(x(:,1),x(:,2), 'poly2'), xs_below_spec, 'uni', false);

quad_coef2=cellfun(@(x) coeffvalues(x), quad_fit2, 'uni', false);

quad_exp2=cellfun(@(x)x(1), quad_coef2, 'uni', false);

disp('Truncated valley quadratic curve fits computed')

toc

\% Full Valley Power Law Curve Fitting

$\%$ isolates left side of valley and flips for power fit leftcurve =cellfun(@(x,y,z) flipud $(\mathrm{x}(\mathrm{y}: \mathrm{z}, \mathrm{:})), \mathrm{xs} \_$int, left_peak, valmin_loc, 'uni', false $)$;

$\%$ replaces empty cells with dummy variables; recasts $\mathrm{x}$ values in ascending order from 1 


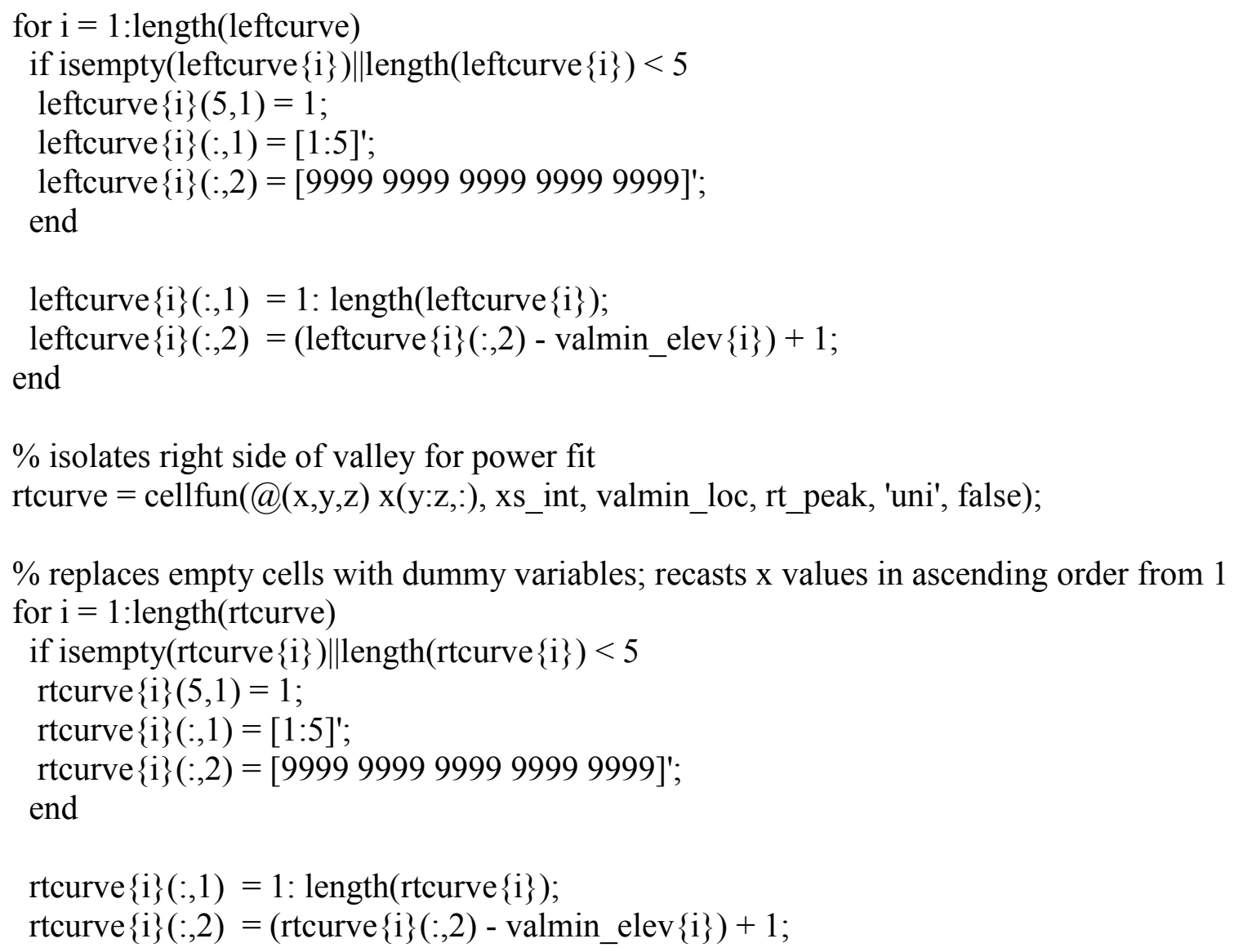

end

$\%$ sets options for power fitting

$\mathrm{ft}=$ fittype( 'power1' );

opts.Algorithm = 'Levenberg-Marquardt';

opts.Display = 'Off';

opts.Lower $=[$-Inf -Inf];

opts.Robust = 'Bisquare';

opts.Upper = [Inf Inf $]$;

opts $=$ fitoptions $(\mathrm{ft})$;

$\%$ calculates power fit for each side of a given cross section [leftfit, lgof]= cellfun(@(x) fit $((x(:, 1)),(x(:, 2)), \mathrm{ft}$, opts $)$, leftcurve, 'uni', false $)$; [rtfit, rgof] = cellfun $(@(x)$ fit $((x(:, 1)),(x(:, 2)), \mathrm{ft}$, opts $)$, rtcurve, 'uni', false $)$; 


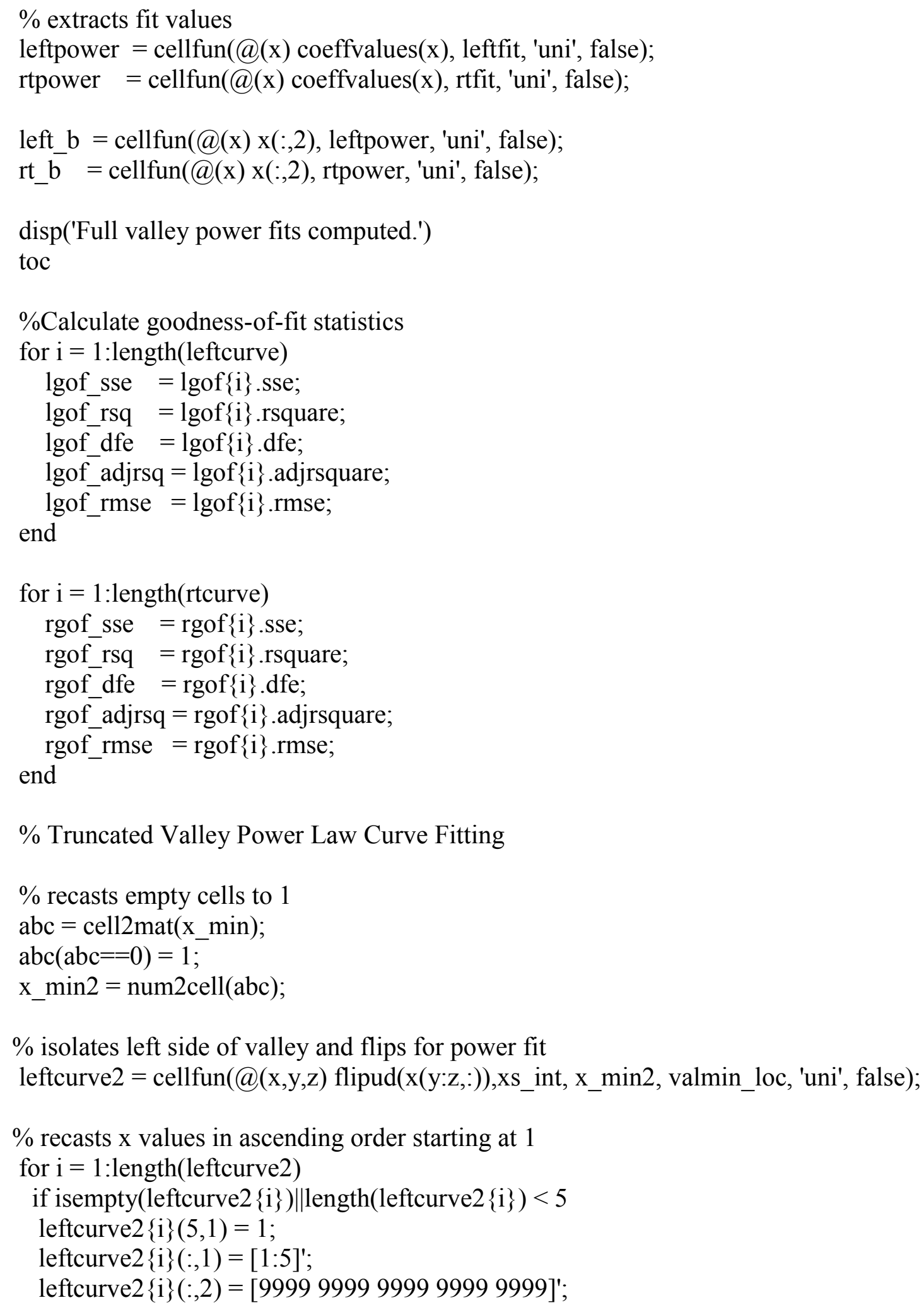


end

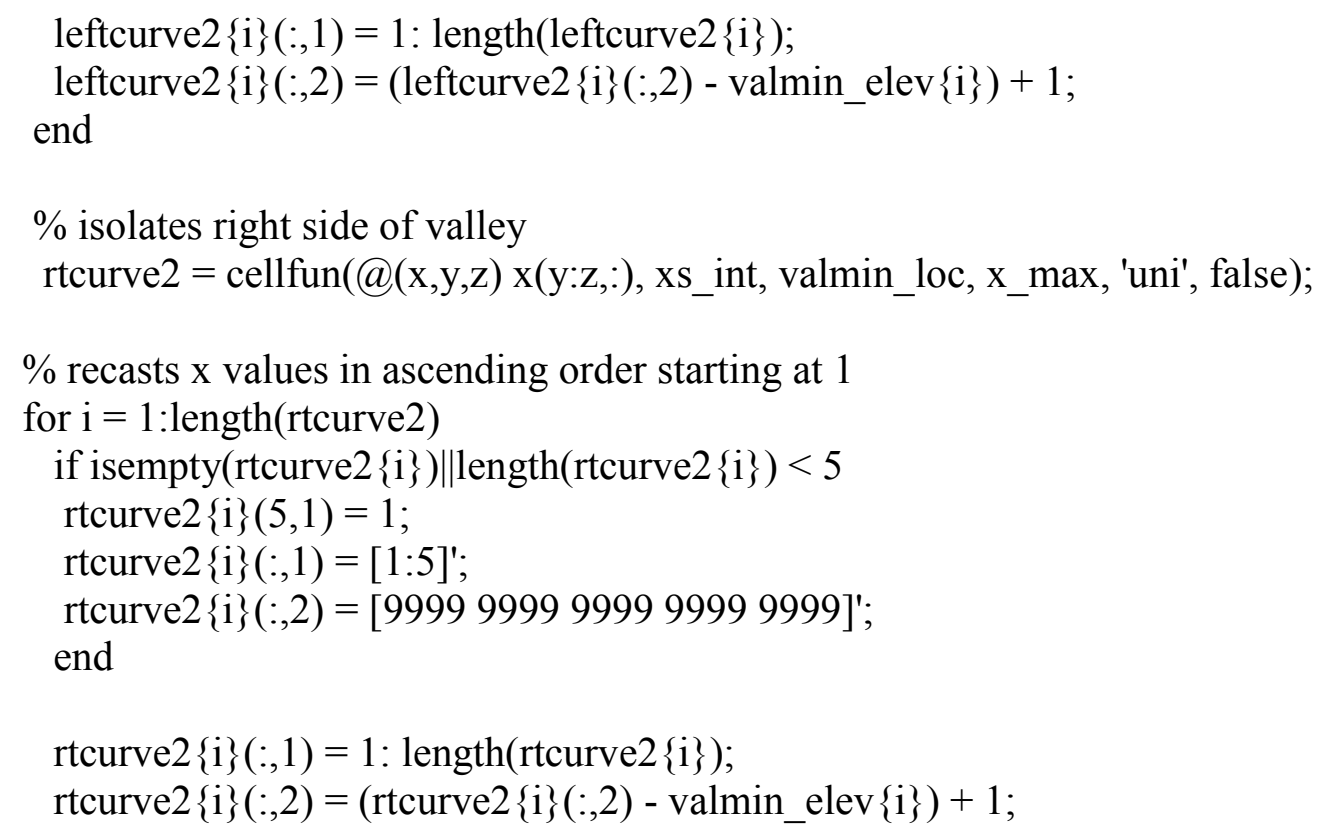

end

[leftfit2, lgof2]= cellfun(@(x) fit ( $(x(:, 1)),(x(:, 2)), \mathrm{ft}$, opts $),$ leftcurve2, 'uni', false); [rtfit2, rgof2]= cellfun $(@(x)$ fit $((x(:, 1)),(x(:, 2)), \mathrm{ft}$, opts $)$, rtcurve2, 'uni', false $)$;

leftpower2=cellfun(@(x) coeffvalues(x), leftfit2, 'uni', false);

rtpower2=cellfun(@(x) coeffvalues(x),rtfit2, 'uni', false);

left_b2=cellfun(@(x)x(:,2), leftpower2, 'uni', false);

rt_b2 = cellfun(@(x)x(:,2), rtpower2, 'uni', false);

disp('Power fits below specified height computed.')

toc

\section{\% 7. EXPORT DATA}

$\%$ combines all metrics in a new matrix

UV_data= cell2mat(cellfun(@(x,y,z,a,b,c,d,e,f,g,h,i,j,k,l,m,n,o) cat (2,x,y,z,a,b,c,d,e,f,g,h,... $\mathrm{i}, \overline{\mathrm{j}}, \mathrm{k}, 1, \mathrm{~m}, \mathrm{n}, \mathrm{o})$, Line_ID, $\mathrm{V}$-index, shape_ratio, shape_ratio2, left_b, left_b2, rt_b,... rt_b2, quad_exp, quad_exp2, left_peak, left_rise, rt_peak, rt_rise, min_relief,... valley_width, spec_width, UV_area, 'uni', false)); 
$\%$ writes output file with header

fid $=$ fopen(outputfile, 'wt');

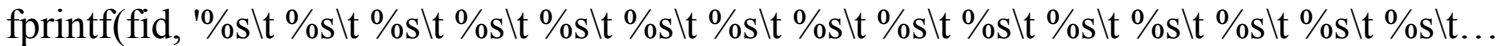

$\% s \backslash t \% s \backslash t \% s \backslash r \backslash n$ ', 'Line_ID', 'V-index', 'shape_ratio_trunc', 'shape_ratio_nat','left_b_nat',...

'left_b_trunc', 'rt_b_nat', 'rt_b_trunc', 'quad_nat', 'quad_trunc', 'left_peak','left_rise',...

'rt_peak','rt_rise', 'min_relief', 'valley_width','spec_width', 'UV_area');

dlmwrite(outputfile, $\overline{\mathrm{UV}}$ _data, '-append', 'delimiter', '\t')

fclose(fid);

$\%$ optional curve fit statistics (requires new output filename)

$\%$ Fit_data=cell2mat(cellfun(@(x) cat $(2, x, y, z, a, b, c, d, e, f, g, h)$, Line_ID, lgof_sse,... lgof_rsq, lgof_dfe, lgof_adjrsq, lgof_rmse, rgof_sse, rgof_rsq, rgof_dfe, rgof_adjrsq,... rgof_rmse, 'uni', false));

disp('Processing complete.')

toc

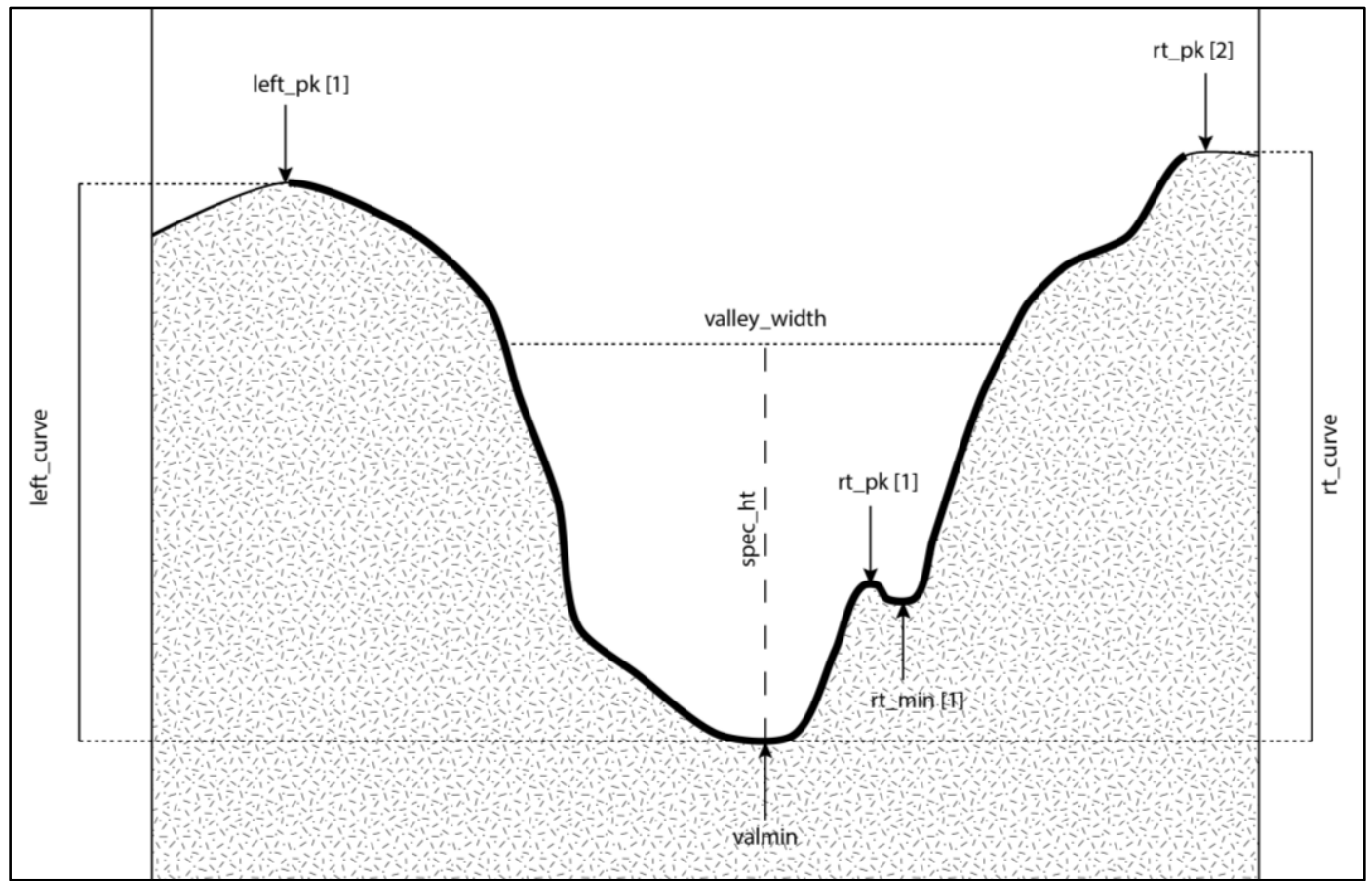

Figure 10. Diagram illustrating major variables encoded by the script 